\title{
Effect of local stress fields on twin characteristics in HCP metals
}

\author{
M. Arul Kumar ${ }^{1}$, I.J. Beyerlein ${ }^{2}$, C. N. Tomé ${ }^{1}$ \\ ${ }^{1}$ Materials Science and Technology Division, Los Alamos National Laboratory, Los Alamos, \\ NM 87545, USA \\ ${ }^{2}$ Theoretical Division, Los Alamos National Laboratory, Los Alamos, NM 87545, USA
}

\begin{abstract}
We study the effect of nearest neighboring grains on the propensity for $\{1012\}$ twin growth in $\mathrm{Mg}$ and $\mathrm{Zr}$. Twin lamellae lying within one grain flanked by two neighboring grains with several orientations are considered. The fields of resolved shear stress on the twin system are calculated in the multicrystal using a three-dimensional full-field crystal plasticity Fast Fourier Transform approach. The calculations were carried out for $\mathrm{Mg}$ and $\mathrm{Zr}$ using slip threshold stresses corresponding to $300 \mathrm{~K}$ and $76 \mathrm{~K}$, respectively, where twin activity is important. We show that the neighboring grain constraint tends to oppose further growth and that the critical applied stress needed to overcome this resistance depends on neighboring grain orientation, more strongly in $\mathrm{Zr}$ than in $\mathrm{Mg}$. We also present results for a pair of adjacent and parallel twins at various spacings. It is found that their paired interaction increases the resistive forces for twin growth above that for an isolated twin. The critical spacing above which this enhanced resistance is removed is smaller for $\mathrm{Zr}$ than $\mathrm{Mg}$. Our analysis reveals that these two disparate responses of $\mathrm{Zr}$ and $\mathrm{Mg}$ are both a consequence of the fact that $\mathrm{Zr}$ is elastically and plastically more anisotropic than $\mathrm{Mg}$. Additional calculations carried out on Ti support this conclusion. These findings can help explain why, for the same grain size, more twins per grain form in $\mathrm{Zr}$ than in $\mathrm{Mg}$, twins in $\mathrm{Zr}$ tend to be thinner than those in $\mathrm{Mg}$, and the relationship between the thickness of the twin and its Schmid factor in $\mathrm{Zr}$ is not as strong as in $\mathrm{Mg}$.
\end{abstract}

Keywords: plasticity, magnesium, zirconium, titanium, and anisotropy

\section{Introduction}

The plastic deformation of hexagonal close packed (HCP) metals occurs by a combination of plastic dislocation glide and deformation twinning [1-5]. Dislocation glide is spatially more homogenous than twinning and lattice re-orientation is gradual. Glide activity can be directly observed by a microscopic analysis of slip traces or indirectly inferred from polycrystal simulations of texture and stress-strain evolution [6-8]. Deformation twins form easily in HCP metals when deformed at or below room temperature [9-11] and, in contrast to 
dislocation glide, they accommodate strain by creating a lamellar shaped domain in which lattice re-orientation and localized shear are significant $[4,12]$. The most commonly observed twin type in HCP metals is the $\{10-12\}<0111>$ tensile twin [11, 13-15]. In Mg, for instance, the c/a ratio is 1.624 , the $\mathrm{c}$-axis re-orientation is $86.3^{\circ}$ and the local shear strain associated with this twin is $13.6 \%$.

Several post-mortem characterization studies of deformed materials have shown that deformation twin lamellae vary significantly in number per grain and in thickness from grain to grain across the microstructure $[9,13-14,16-20]$. Such analyses were able to correlate the number of twins per grain and twin thickness with the size and orientation of the parent grain $[13-14,21]$. Generally it is found that the larger grains contain more twins and grains more suitably oriented for twinning contain thicker twins [13-14, 22-25]. These results are consistent with those of many prior studies that use other characterization methods and report that twin volume fractions decrease with reductions in average grain size or that most (but not all) of the twin variants observed correspond to the one with the highest Schmid factor [26-27].

While such microstructure/twinning relationships appear to apply to a variety of HCP materials, many details of the twinning characteristics depend sensitively on the material in ways that are not apparent or intuitive [13-14, 24-25]. Take for example, statistical correlations reported for $\{1012\}$ twins in $\mathrm{Mg}$ and $\mathrm{Zr}$ [13-14]. These two metals were highpurity and had similar initial rolling texture and grain boundary misorientation distribution. At and below room temperature both $\mathrm{Mg}$ and $\mathrm{Zr}$ twin profusely via $\{1012\}$ twinning when compressed in-plane, a direction that places the basal poles of many grains in tension. Postmortem EBSD characterization of $\{1012\}$ twins after a few percent strain showed that both metals exhibit remarkably similar relationships between the number of twins per grain and twin thickness and the grain size and orientation. For $\mathrm{Mg}$, the average twin thickness increased from approximately 1 micron to 4 microns when the twin Schmid factor increased from 0.05 to 0.5. In the case of $\mathrm{Zr}$, however, the correlation between average twin thickness and twin Schmid factor was not as strong: twin thickness varied from approximately 0.2 microns to 0.3 microns as twin Schmid factor increased from 0.05 to 0.5 . Also, in $\mathrm{Mg}$ the number of twins per twinned grain varied from 1 to 2 as the grain area increased from 250 to $500 \mu \mathrm{m}^{2}$, whereas in $\mathrm{Zr}$ the number of twins per twinned grain increased from 2 to 15 for the range of grain area from 50 to $500 \mu \mathrm{m}^{2}$. These results show that twins in $\mathrm{Mg}$ are almost ten times thicker than the twins in $\mathrm{Zr}$ and that more twins tend to develop in $\mathrm{Zr}$ than $\mathrm{Mg}$ for the same grain size. 
Given the conventional understanding, there exists no compelling reason to expect that the absolute number and thickness of $\{1012\}$ twins would be the same for the same grain orientation and size. Many other microstructural variables like texture, grain boundary character, alloying additions, can come into play [13-14, 28-30], as well as possible differences in deformation conditions, such as applied strain level, strain rate, and temperature [29, 31-37]. Yet, whether the volume fraction of twinning is distributed over many fine twins or fewer thick twins can have a profound effect on macroscopic yield stress, flow stress, and hardening rates [38-41]. Thus, it is desirable to attain a better understanding of the underlying mechanisms and key variables that govern twin thickness and number of twins per grain.

To gain some insight into the observed differences in $\{1012\}$ twin morphology between $\mathrm{Mg}$ and $\mathrm{Zr}$ (and eventually other HCP metals), we employ a micromechanics crystal plasticity based simulation tool to calculate the local stress states around twin lamellae. Specifically, we use a full-field, crystal plasticity based Fast Fourier Transform approach (CP-FFT) that was recently extended to account for the shear strains and reorientations characteristic of deformation twins in HCP metals [42]. We set up the model in order to understand the driving forces for twin expansion (twin growth) after the twin has propagated and been stopped by grain boundaries. We study the driving forces for twin growth as a function of its neighboring grain orientation. The simulations reveal that the constraint that the neighboring grain places on twin transformation generates forces within the twin that resist its growth. The magnitude of these backstresses depends on the neighboring grain orientation, more sensitively in $\mathrm{Zr}$ than $\mathrm{Mg}$. To study the effects of material properties on the number of twins per grain, we performed mechanics calculations involving two interacting parallel twin lamellae within the same grain as a function of twin spacing. The results reveal that the forces opposing growth are higher than those for an isolated twin. The critical spacing beyond which this hampering effect diminishes is smaller for $\mathrm{Zr}$ than $\mathrm{Mg}$. These results provide insight into why twin Schmid factor and twin thickness is highly correlated in $\mathrm{Zr}$ but less so in $\mathrm{Mg}$ and why more twins per grain tend to form in $\mathrm{Zr}$ than in $\mathrm{Mg}$ for the same grain size.

\section{Numerical method: The CP-FFT approach}

The original Fast Fourier Transform (FFT) method was developed to study the local and effective mechanical response of non-linear composite materials [43] and later adapted by Lebensohn [44] to simulate the deformation behavior of polycrystalline metals. Over the past decade, the FFT method has been advanced to a crystal plasticity based model (CP-FFT) 
enabling the calculation of the spatially resolved mechanical fields resulting from a distribution of crystals, and the associated directional dependence of their elastic and plastic properties. [45-50]. The CP-FFT approach is an iterative process of adjusting a compatible strain field to a locally equilibrated stress field, both related through a crystal plasticity based constitutive relationship. The version of CP-FFT that we employ here accounts for a material with infinitesimal elasto-visco-plastic constitutive behavior and the shear transformation induced within a twin lamella [42]. For reference, it is briefly revisited below.

The constitutive behavior of an elasto-visco-plastic material under an infinitesimal strain approximation with shear transformation can be written as

$$
\boldsymbol{\sigma}(\mathbf{x})=\mathrm{C}(\mathbf{x}): \varepsilon^{\mathrm{el}}(\mathbf{x})=\mathrm{C}(\mathbf{x}):\left(\boldsymbol{\varepsilon}(\mathbf{x})-\varepsilon^{\mathrm{pl}}(\mathbf{x})-\varepsilon^{\mathrm{tr}}(\mathbf{x})\right)
$$

where $\boldsymbol{\sigma ( x )}$ is the Cauchy stress, $\mathbf{C}(\mathbf{x})$ is the elastic stiffness tensor, and $\boldsymbol{\varepsilon}^{\mathrm{el}}(\mathbf{x})$ is the elastic strain at a material point $\mathbf{x}$. The elastic strain can be written as the difference between the total strain $\boldsymbol{\varepsilon}(\mathbf{x})$, and the plastic strain $\boldsymbol{\varepsilon}^{\mathrm{pl}}(\mathbf{x})$ due to crystallographic slip and the transformation strain $\boldsymbol{\varepsilon}^{\text {tr }}(\mathbf{x})$. In this work, we consider deformation twinning as a shear transformation process. We solve the problem to obtain a local stress field at material point $\mathbf{x}$ by using an implicit time discretization of the form:

$$
\boldsymbol{\sigma}^{\mathrm{t}+\Delta \mathrm{t}}(\mathbf{x})=\mathbf{C}(\mathbf{x}):\left(\boldsymbol{\varepsilon}^{\mathrm{t}+\Delta \mathrm{t}}(\mathbf{x})-\boldsymbol{\varepsilon}^{\mathrm{pl}, \mathrm{t}}(\mathbf{x})-\dot{\boldsymbol{\varepsilon}}^{\mathrm{pl}, \mathrm{t}+\Delta \mathrm{t}}\left(\mathbf{x}, \boldsymbol{\sigma}^{\mathrm{t}+\Delta \mathrm{t}}\right) \Delta \mathrm{t}-\boldsymbol{\varepsilon}^{\mathrm{tr}, \mathrm{t}}(\mathbf{x})-\Delta \boldsymbol{\varepsilon}^{\mathrm{tr}, \mathrm{t}+\Delta \mathrm{t}}(\mathbf{x})\right)
$$

where,

$$
\begin{aligned}
& \cdot \mathrm{pl}^{\mathrm{pl}}(\mathbf{x})={ }_{\mathrm{s}=1}^{\mathrm{N}} \mathbf{m}^{\mathrm{s}}(\mathbf{x})^{\cdot \mathrm{s}}(\mathbf{x}) \\
& \dot{\gamma}^{\mathrm{s}}(\mathbf{x})=\dot{\gamma}_{\mathrm{o}}\left(\frac{\left|\mathbf{m}^{\mathrm{s}}(\mathbf{x}): \sigma(\mathbf{x})\right|}{\tau_{\mathrm{c}}^{\mathrm{s}}}\right)^{\mathrm{n}} \times \operatorname{sgn}\left(\mathbf{m}^{\mathrm{s}}(\mathbf{x}): \sigma(\mathbf{x})\right)
\end{aligned}
$$

where ${ }^{\cdot s}$ and $\tau_{\mathrm{c}}^{\mathrm{s}}$ are the shear rate and the critical resolved shear stress associated with each of the slip systems 's', respectively. During the build-up of the twinning transformation, the change in transformation strain is given by

$$
\Delta \varepsilon^{\mathrm{tr}}(\mathbf{x})=\mathbf{m}^{\mathrm{tw}}(\mathbf{x}) \Delta \gamma^{\mathrm{tw}}(\mathbf{x})
$$


Otherwise, it is zero. In Eqs. (3-5), $\mathbf{m}^{\mathrm{s}}=\frac{1}{2}\left(\mathbf{b}^{\mathrm{s}} \otimes \mathbf{n}^{\mathrm{s}}+\mathbf{n}^{\mathrm{s}} \otimes \mathbf{b}^{\mathrm{s}}\right)$, is the Schmid tensor and $\mathbf{b}^{\mathrm{s}}$ and $\mathbf{n}^{\mathrm{s}}$ are unit vectors along the Burgers vector and slip plane normal slip directions. The integer $n$ is the stress exponent, and $\mathbf{m}^{\text {tw }}=\frac{1}{2}\left(\mathbf{b}^{\text {tw }} \otimes \mathbf{n}^{\text {tw }}+\mathbf{n}^{\text {tw }} \otimes \mathbf{b}^{\text {tw }}\right)$ is the Schmid tensor associated with the twinning system. The unit vectors $\mathbf{b}^{\text {tw }}$ and $\mathbf{n}^{\text {tw }}$ are directed along the twinning direction and the twin plane normal, respectively. For points $\mathbf{x}$ within the twin domain, the twinning transformation is achieved via $\mathrm{N}^{\text {twincr }}$ increments of shear strain, according to $\Delta \gamma^{\mathrm{tw}}(\mathbf{x})=\frac{\mathrm{s}^{\mathrm{tw}}}{\mathrm{N}^{\mathrm{twincr}}}$

Until reaching the characteristic twinning shear $\mathrm{s}^{\mathrm{tw}}$. The time increment, $\Delta \mathrm{t}=10^{-4} \mathrm{~s}$ and the number of increments to achieve the twinning transformation $\mathrm{N}^{\text {twincr }}$ are set sufficiently low and high, respectively, to ensure convergence.

\subsection{Tri-crystal set up:}

We apply CP-FFT to the tri-crystal model shown in Fig. 1. The tri-crystal is comprised of the parent grain (grain 1), which will contain the twin lamellae (only one lamella is shown schematically). The simulation unit cell is columnar along x-axis. The Euler angles of the parent grain are $\left(0^{\circ}, 0^{\circ}, 0^{\circ}\right)$, meaning the c-axis is aligned along the $\mathrm{z}$-direction. It contains the specific tensile twin variant (01-12)[0-111]. The parent is flanked on each side by two neighboring grains equally oriented (grain 2). The orientation of grain 2 will be varied in our simulations. A homogeneous buffer layer with a random texture surrounds the tri-crystal and represents the bulk material response. The buffer layer does not cover the tri-crystal setup on the two sides (front and back) of the ZY planes.

This tri-crystal unit cell is subjected to compression along the y-direction (see Fig. 1), which is perpendicular to the c-axis of the parent grain. Along the $\mathrm{x}$ and $\mathrm{z}$ directions, we enforce zero average stress. This 3D stress state corresponds to a Schmid factor of $\sim 0.5$ for the (01-12)[0-111] tensile twin variant modeled. By fixing the parent grain c-axis along the $\mathrm{z}$ direction leads to the situation where the twin plane normal and twin shear directions of the modeled tensile twin variant is only in the $y-z$ plane. There is no out-of-plane twin shear in $x-y$ and $\mathrm{x}-\mathrm{z}$ planes. The inclination of the twinning plane with respect to the compression axis is $43.1^{\circ}$ and $42.6^{\circ}$ for $\mathrm{Mg}$ and $\mathrm{Zr}$, respectively. While the cell is under the applied strain state, the 
corresponding twin shear transformation within the twin domain is performed in two steps: first, the set of voxels pre-selected for the twin domain are reoriented and, next, the local twinning shear is enforced within these voxels in several increments $\left(\mathrm{N}^{\mathrm{twincr}}=2000\right.$ in Eq. (6)). The 'strain hold' boundary condition will lead to some applied stress relaxation following the twin transformation, and is appropriate for simulating grains that are embedded in the bulk of the aggregate.

The tri-crystal unit cell is assumed to be periodic in all three directions and it is discretized into $510 \times 510 \times 3$ voxels with a buffer layer 25 voxels thick, which is sufficient to capture the spatially resolved stress distribution unaffected by boundary conditions. A set of six voxels in grain 1 is preselected as the twin domain thickness, which corresponds to a twin volume fraction of $\sim 1.3 \%$ in the parent grain. The twin domain is defined by two parallel interfaces that represent the crystallographic twinning plane. Additional CP-FFT simulations were performed with different twin volume fractions and different size simulation cells. We find that they give qualitatively similar results as those we report here.

The calculated stress and strain tensors are the result of strains from anisotropic elasticity and crystallographic slip. In particular, we will focus on the stress fields generated by enforcing traction and displacement continuity conditions at the grain boundary, twin lamella boundary, and grain boundary/twin boundary junctions. The model tri-crystal is idealized such that the grain boundaries and twin boundaries are planar and flat. As this is a meso-scale micromechanics model, atomic scale defects in the grain boundary are not modeled.

The same CP-FFT tri-crystal calculations will be performed for both $\mathrm{Zr}$ and $\mathrm{Mg}$ (and later Ti) in order to compare their stress fields. For both metals, we input into the crystal plasticity simulations the actual elastic moduli, the active slip modes, and the CRSS values for activating them. These values are presented in Table 1 for $\mathrm{Mg}$ at room temperature and $\mathrm{Zr}$ at $77 \mathrm{~K}$, which are the deformation temperatures needed for pervasive twinning.

Although sharing the same crystal structure, $\mathrm{Zr}$ and $\mathrm{Mg}$ are significantly different in their elastic and plastic behavior. Firstly, $\mathrm{Zr}$ is more elastically anisotropic than $\mathrm{Mg}$. Mg has elastic anisotropic indices of $0.98,1.11$ and 1.21 , whereas $\mathrm{Zr}$ has anisotropic indices of 0.78 , 
1.11 and $1.47\left[^{51}\right]^{1}$. Secondly, $\mathrm{Zr}$ is more plastically anisotropic than $\mathrm{Mg}$. $\mathrm{Zr}$ has less available slip families with only two that are practically available at moderate strain levels: prismatic $<\mathrm{a}>$ slip, being the easier one, and pyramidal $<\mathrm{c}+\mathrm{a}>$ slip, the harder one. In contrast, $\mathrm{Mg}$ has three modes that are available, with basal $<\mathrm{a}>$ slip being the easiest, prismatic $<\mathrm{a}>$ slip harder, and pyramidal $\langle\mathrm{c}+\mathrm{a}\rangle$ slip, the hardest. The simulations use a constant, non-evolving CRSS value for slip on each slip system (see Table 1) since the calculations involve relatively small straining of a few percent. In such cases, work hardening and lattice re-orientations due to crystallographic slip are not crucial, although these effects could easily be taken into account into this model should larger strain simulations be desired. In this work we are not allowing for work hardening and lattice rotations.

\begin{tabular}{|c|c|c|c|c|c|c|c|c|c|}
\hline \multirow{2}{*}{ Material } & \multicolumn{4}{|c|}{ Elastic constants (GPa) } & \multicolumn{3}{c|}{ CRSS values of slip modes (MPa) } \\
\cline { 2 - 10 } & $\mathrm{C} 11$ & $\mathrm{C} 12$ & $\mathrm{C} 13$ & $\mathrm{C} 33$ & $\mathrm{C} 44$ & $\begin{array}{c}\text { Basal } \\
<\mathbf{a}>\end{array}$ & $\begin{array}{c}\text { Prismatic } \\
<\mathbf{a}>\end{array}$ & $\begin{array}{c}\text { Pyramidal } \\
<\mathbf{c}+\mathbf{a}>\end{array}$ & $\begin{array}{c}\mathrm{T} \text {. } \\
\text { Twin }\end{array}$ \\
\hline $\mathrm{Mg}$ & 59.75 & 23.24 & 21.70 & 61.70 & 16.39 & 3.3 & 35.7 & 86.2 & 20.0 \\
\hline $\mathrm{Zr}$ & 143.5 & 72.50 & 65.40 & 164.9 & 32.10 & 700.0 & 20.0 & 160.0 & 102.0 \\
\hline $\mathrm{Ti}$ & 162.4 & 92.00 & 69.00 & 180.7 & 46.70 & 120.0 & 60.0 & 180.0 & 125.0 \\
\hline
\end{tabular}

Table 1: The elastic constants [52] and the critical resolved shear stresses (CRSS) values for different plastic modes used in the calculation for $\mathrm{Mg}$ [53], $\mathrm{Zr}$ [54-55] and $\mathrm{Ti}$ [20,56-57]. Only slip modes are considered for the accommodation of plastic deformation.

For both metals, the characteristic CRSS for $\{1012\}$ twinning lies between the easiest and second easiest slip mode. For $\mathrm{Mg}$, it is $20 \mathrm{MPa}$, being seven times harder than basal slip, and for $\mathrm{Zr}$, it is $102 \mathrm{MPa}$, being five times harder than prismatic slip. The second hardest slip mode, which is prismatic slip for $\mathrm{Mg}$ and pyramidal slip for $\mathrm{Zr}$, is $\sim 10$ times that of the corresponding easiest slip mode. This simple comparison perhaps provides some explanation as to why the deformation twinning is preferred in both metals.

To interpret the results and infer the driving forces for further twin growth, we calculate the resolved shear stress, TRSS, along the twinning direction for the twin variant in the parent

${ }^{1}$ Anisotropic indices are defined as the ratios of the eigenvalues of the elastic stiffness [51] tensor as: $\alpha=\left(\mathrm{C}_{11}+\mathrm{C}_{12}-\mathrm{C}_{33}\right) / \mathrm{C}_{13}, \beta=\mathrm{C}_{66} / \mathrm{C}_{44}, \gamma=\mathrm{C}^{(1)} / 2 \mathrm{C}_{44}$

Where $C^{(1)}=\left(\mathrm{C}_{33}+\mathrm{C}_{11}+\mathrm{C}_{12}\right) / 2-\left(\mathrm{C}_{13} \operatorname{sqrt}\left(\alpha^{2}+8\right)\right) / 2$ 
grain, and compare it to a characteristic CRSS for $\{1012\}$ twinning. While part of the analysis, comparing the TRSS with a CRSS is not used to actually grow the twin in the simulation. We are aware that the atomic-scale mechanisms underlying twin growth are still being intensely studied and remain to be clarified. On the one hand, molecular dynamics (MD) simulations and TEM evidence show that twin boundary (TB) migration takes place via the glide of twinning dislocations on coherent twin boundary planes, combined with climb of disconnections on basal-prism (BP) facets that give the twin boundary a serrated appearance. Both processes can be driven by the TRSS, the former directly through the RSS [58-59] and the latter through the stress normal to the BP plane that is associated with the RSS [60-67]. From this perspective, and considering that both mechanisms need to be active for the twin to grow, the notion of a CRSS associated with twin activation refers to an effective RSS. One advantage of our calculations is that the full stress and strain tensors can be calculated and, thus, all stress components acting on the twin interface can easily the determined.

\section{Results}

Fig. 2a shows the TRSS field in the $\mathrm{Zr}$ tri-crystal for a grain neighbor with the orientation $\left(75^{\circ}, 62^{\circ}, 0^{\circ}\right)$. Before twinning, under a compressive strain of 0.0025 , the TRSS field is uniform within the parent and the neighboring grain. The difference in TRSS across the grain boundaries seen here is due to their difference in orientation. The average TRSS in the parent is $109.43 \mathrm{MPa}$, which is greater than the CRSS for twinning. When a lamella in the center of the parent grain transforms into a twin under this same strain (see Fig. 1), the TRSS field becomes inhomogeneous (Fig. 2a). The lattice reorientation and twin shear within the twin lamella in the case of $\mathrm{Zr}$ is $85.3^{\circ}$ and $16.6 \%$, respectively.

In Fig. 2a, three general regions can be identified that are relevant for subsequent twinning. The first one (labeled A) lies in the vicinity of the twin, where the sign of the TRSS has reversed, against that which would promote expansion of the same twin. The second one (labeled B) corresponds to the region away from the twin in the parent, where the stress field is similar to the one before twinning and a new twin could potentially form. The last region of interest (labeled C) is the one in the neighboring grain at the twin tip/grain boundary junction, where the stress concentration could potentially drive transmission of the same twin into the neighboring grain. In this work, we study the first two possibilities, associated with the labels $\mathrm{A}$ and B, separately by calculating the TRSS fields in both $\mathrm{Zr}$ and Mg. 


\subsection{Single twin growth}

Fig. $2 \mathrm{~b}$ shows the TRSS profile along the twin boundary (TB) corresponding to the calculation in Fig. 2a for Zr. As shown, following transformation, the sign of the TRSS is reversed along the twin length. The difference between the values of the TRSS before and after the twin has formed under the same applied strain can be viewed as a backstress $S_{B}$. This $S_{B}$ is most severe at the junction between the twin tip and grain boundary, where the neighboring grain is reacting to the localized twin shear imposed by the twin lamella. The $S_{B}$ decays with distance from the junction into the parent grain interior and reaches its minimum at the center of the twin. This twin is not expected to experience the driving force it needs to grow further under the current state. To expand the twin, the remotely applied stress needs to be increased, which will raise the RSS distribution in Fig $2 b$. The part of the twin most likely to reach the CRSS value for growth (102 MPa for $\mathrm{Zr}$ ) first will be the center of the twin, since this is where $S_{B}$ is minimal.

To study the driving forces for further twin expansion, we calculate the $S_{T B}$, which is the TRSS at the central part of the TB, shown as region $\Sigma$ in Fig. 1 and Fig. 2b, as it evolves with the applied stress. The $S_{T B}$ was determined by taking the average of the TRSS in the six voxels spanning the center of the TB. To elucidate the effects of neighbor orientation, these deformation simulations were performed for the same parent grain and twin, but with six different neighbor orientations as well as a hypothetical "single crystal" case where the neighbor orientation equals that of the parent (see Table 2). The neighbor orientations were selected to cover a broad range of plastic response. Specifically, the crystallographic orientations of the neighbors varied such that two were oriented predominantly for basal $\langle a\rangle$ slip, three for prismatic <a> slip, and the remaining two for pyramidal $<\mathrm{c}+\mathrm{a}>\mathrm{slip}$.

\begin{tabular}{|c|c|c|c|c|c|}
\hline \multirow{2}{*}{ Case } & \multirow{2}{*}{$\begin{array}{c}\text { Euler angles of } \\
\text { neighbor } \\
\text { [Degrees] }\end{array}$} & \multirow{2}{*}{ Crystal frame } & \multicolumn{3}{|c|}{$\begin{array}{l}\text { Relative position along twin direction of the best } \\
\text { oriented slip system }\end{array}$} \\
\hline & & & Basal & Prismatic & Pyramidal $(c+a)$ \\
\hline 0 & $0,0,0$ & & 0.4609 & 0.2161 & 0.8651 \\
\hline 1 & $75,62,0$ & & 0.8652 & 0.1528 & 0.5436 \\
\hline
\end{tabular}




\begin{tabular}{|c|c|c|c|c|c|}
\hline 2 & $30,0,0$ & & 0.5322 & 0.2161 & 0.8356 \\
\hline 3 & $0,90,0$ & & 0.4052 & 0.2161 & 0.8996 \\
\hline 4 & $0,30,0$ & & 0.8212 & 0.0960 & 0.4191 \\
\hline 5 & $45,60,30$ & & 0.7901 & 0.4313 & 0.4891 \\
\hline 6 & $50,43,30$ & & 0.8866 & 0.2869 & 0.3914 \\
\hline
\end{tabular}

Table 2. Neighbor grain crystallographic orientations along crystal frame and the corresponding relative position along twin direction of the best oriented slip systems for each mode. The relative position is defined as: $\mathrm{m}=$ $\left(\mathbf{b}_{\mathbf{t}} \cdot \mathbf{b}_{\mathbf{s}}\right)\left(\mathbf{n}_{\mathbf{t}} \cdot \mathbf{n}_{\mathbf{s}}\right)$; where $\mathbf{b}_{\mathbf{t}}$ and $\mathbf{n}_{\mathbf{t}}$ is the twin direction and twin plane normal. $\mathbf{b}_{\mathbf{s}}$ and $\mathbf{n}_{\mathbf{s}}$ is the slip direction and slip plane normal [68]. The crystal wireframe of the neighbor orientations looking along the $\mathrm{z}$-axis.

Fig 3a presents the strain evolution of $S_{T B}$, normalized by the CRSS for twinning, for the $\mathrm{Mg}$ tri-crystal. For the same twin variant, the lattice reorientation and twin shear for $\mathrm{Mg}$ is $86.3^{\circ}$ and $13 \%$, respectively. Before additional strain is applied, $S_{T B}$ is close to zero for all cases. As additional strain is imposed, $S_{T B}$ evolves non-linearly as a result of the development of plasticity in the localized region around the twin tip/GB junction. In all six cases, it is possible to raise the applied stress such that eventually the $S_{T B}$ exceeds the CRSS for twinning. However, the strain evolution of $S_{T B}$ exhibits a dependence on the neighboring grain orientation. Specifically, the neighboring grain oriented for the easiest basal slip $\left(0^{\circ}, 30^{\circ}, 0^{\circ}\right)$ provides the lowest $S_{B}$ and less additional stress needs to be applied in order for $S_{T B}>$ CRSS. In contrast, the neighbor oriented for the harder pyramidal slip $\left(30^{\circ}, 0^{\circ}, 0^{\circ}\right)$ generates the highest $S_{B}$ and hence more stress is required to overcome it and grow the twin. Only the neighboring orientation varied in these calculations while the parent grain and twin orientation remained fixed. Thus, an important implication from these calculations is that criteria based on parent grain properties alone, such as orientation, twin variant, and average grain stress, may not be sufficient to determine whether freshly formed twins would grow under the applied stress. Although these six cases are far from representing the entire space of neighboring grain orientations, these results indicate that thickening of twins in $\mathrm{Mg}$ is possible despite the 
significant differences in the plastic behavior of the neighboring grains. This conclusion is consistent with several experimental studies that have reported on the relatively large thickness of $\{1012\}$ twins in $\mathrm{Mg}$, expanding in some cases to overtake the grain, as the stress is increased [13].

The results for $\mathrm{Mg}$ can be compared with the same calculations of $S_{T B}$ for the same six neighbors (normalized by CRSS) for Zr shown in Fig. 3b. A notable distinction is that $S_{T B}$ does not evolve in the same manner as in $\mathrm{Mg}$. First, unlike in $\mathrm{Mg}$, the initial values of the backstresses for some neighboring orientations $(\mathrm{C} 2, \mathrm{C} 3, \mathrm{C} 4, \mathrm{C} 6)$ are relatively high, with the ratio $S_{T B}$ /CRSS being well below zero. In some cases the $S_{T B}$ only rises slightly as additional strain is applied, without reaching the CRSS (C3 and C6). In other cases $S_{T B}$ does not evolve or worsens (C2 and $\mathrm{C} 4)$. Only for the remaining two neighboring grain orientations (C1 and $\mathrm{C} 5)$, where $S_{T B} / \mathrm{CRSS}$ is initially positive, can an additional applied stress overcome the backstress and make $S_{T B}$ rise above the CRSS. These outcomes can be connected with the type of slip activated in the neighboring grain at the twin/GB junction. For those neighbors $(\mathrm{C} 1, \mathrm{C} 5$ in Table 2) that support further twin growth with an increase in stress $\left(S_{T B} / \mathrm{CRSS}>1\right)$, the preferred slip mode is prismatic $\langle\mathrm{a}>$ slip, which is the easiest slip mode in $\mathrm{Zr}$, and the backstresses are relatively small in value. In contrast, those oriented for the harder pyramidal $<\mathrm{c}+\mathrm{a}>$ slip mode $(\mathrm{C} 0, \mathrm{C} 2, \mathrm{C} 4$ in Table 2$)$ can make it difficult for subsequent twin expansion, since the backstresses generated are large.

While the number of grain orientations for the parent and neighboring grains studied here is not extensive, and quantitative differences would be expected if more orientations were considered, the relationships revealed by these calculations provide useful insight. First, with all else being the same, the backstresses that develop in the twin in $\mathrm{Zr}$ are more sensitive to the neighboring grain orientation. Second, the values of backstress in $\mathrm{Zr}$ are much larger compared to its CRSS for twinning than those in Mg. These differences may explain why not all grains suitably oriented for twinning form twins in $\mathrm{Zr}$, why twins in $\mathrm{Zr}$ tend to be thinner than those in $\mathrm{Mg}$, and why the relationship between twin thickness and twin Schmid factor in $\mathrm{Zr}$ is not as strong as in $\mathrm{Mg}[13,14]$.

\subsection{Interactions between parallel twins}

As we have seen, twins are heterogeneous domains that generate localized stress fields in the parent and neighboring grain that are significantly different than the average grain stress or the far field stress state. As shown in Fig. 2 a for $\mathrm{Zr}$, the backstress fields extend beyond the 
TB to distances several times the twin thickness, decaying in magnitude with distance from the TB. When multiple twins form in the same grain, their backstress fields can interact depending on their separation, which would impact the driving forces available for growth.

Up to now, the variables that govern twin spacing in a grain have not been given much attention in the literature. In this section, in efforts to gain some insight, the tri-crystal CP-FFT model is applied to study the stress fields that develop when two adjacent, parallel and identical twins exist in the same parent grain. Fig 4 is a schematic of the tri-crystal model, where the twin thickness is $t$ and their spacing $s$, is the minimum distance between their (inner) boundaries $s=n t$, where $n$ is an integer. The two parallel twins together inserted under load and we are not inserting the two twins in sequence.

Fig. 5 shows the TRSS field produced by an isolated twin and a pair of twins with spacing $2 t, 8 t$ and $20 t$ in a $\mathrm{Zr}$ tri-crystal. At $2 t$, when the two twins are closely spaced, their stress fields overlap; when they are spaced 8t apart these fields appear to be on the cusp of interacting; and by $20 t$ their fields seem to be well separated.

More quantitatively, Figs. 6(a)-(c) shows the TRSS distribution profile along the central plane of the twins compared to an isolated twin for $\mathrm{Zr}$. The interaction between the two twins has not changed the fact that the backstress is the largest at the twin tip/GB junction and decays in value toward the center of the grain. However, the backstresses depends on spacing $s$ and, more importantly, their values are higher than that of an isolated twin on average. The interaction increases the backstress, especially when the two twins are closely spaced. This increase in backstress can hamper their growth more so than if these twins were isolated.

To further examine the variation in their backstress with twin spacing $s$, we calculate the average twin TRSS in one of the twin domains, $S_{\text {ave }}$ for different spacings. Using the isolated twin case as the reference, we plot in Fig. 7, the difference between the $S_{\text {ave }}$ and $S_{\text {ave, } 0}$ of an isolated case as a function of spacing $s$. From the calculation in Fig. 7, we can identify a critical spacing between $8 t$ and $10 t$, in which the difference becomes nearly zero for $\mathrm{Zr}$ (Fig 7b). Above this spacing, any additional hampering effects on the TRSS caused by the interaction between these two twins becomes negligible. For $\mathrm{Mg}$, on the other hand, the twintwin interaction effect will hamper propagation even at large separations (Fig 7a).

One contribution to the backstress field acting on the twin comes from the constraint that the neighboring grain provides on the localized shear imposed by the twin lamella. 
Another contribution comes from the reaction in the parent grain to the shear transformation. As we have seen in earlier calculations for an isolated twin, for the same parent and twin and material, the extent of the backstress field depends on the orientation of the grain neighbors. Thus, the neighboring grain properties could possibly affect the interaction between two twins in the parent and hence the critical twin spacing beyond, which their mutual interaction becomes negligible. To examine neighbor effects, we repeat the simulations for neighbor orientations corresponding to cases 1 and 4 (see Table 2). These results are included in Fig. 7. We find that while the grain neighbor affects the magnitude of the backstress field, $S_{a v e}$ evolves with $s$ in a similar manner as with the other neighboring orientations. For $\mathrm{Zr}, S_{\text {ave }}$ reduces to that of the single isolated twin $S_{\text {ave }, 0}$ by $s \sim 9 t$ for cases 1 and 4 . Thus changing the neighbor orientation in these cases does not significantly alter the critical spacing for $\mathrm{Zr}$.

For comparison, Figs. 6(d)-(f) show the TRSS distribution along twin centerline for the pair of twins spaced 2t, 8t, and 20t for Mg. Similar to Figs. 6(a)-(c) for Zr, the backstress generated in each twin of the pair is more intense than that of the isolated twin. The intensity decreases as the spacing between the twins increases. The interesting difference with $\mathrm{Zr}$ is that in $\mathrm{Mg}$ even for a large spacing of $20 t$ the stress fields of these two twins still interact such that the backstress remains higher than that of the isolated twin. To see this more clearly, Fig. 7(a) plots the variation of the difference between $S_{\text {ave }}$ for the two-twin case and $S_{\text {ave, } 0}$ for the isolated twin case with $s$. For all spacings shown from $2 t$ to $20 t$, the interaction between two twins causes an additional backstress over and above that generated within an isolated twin. Further, we find this conclusion applies when considering three different neighbor orientations (case 0 , 1, and 4). Changing the neighbor orientation does not alter the conclusion that the critical spacing for $\mathrm{Mg}$ exceeds $20 t$, which could physically extend beyond the grain size. In $\mathrm{Mg}$, the presence of another twin, even when it is distant (over 20 times in thickness) hampers twin growth more so than if it was isolated.

\section{Discussion}

Grain neighbor effects on twin thickness and spacing. It has been established by prior micromechanics calculations and experimental measurement that introduction of a finite twin domain that extends across a grain connecting opposite grain boundaries generates a stress field that resists subsequent expansion of the twin under the same applied stress state [69-75]. 
In this work, we use these calculations to examine the local driving forces in the twin domain and along the TB that would be relevant to further expand the twin domain.

The simulations on a single twin reveal that driving forces for twin growth in a parent grain for the same twin and parent vary as a function of the orientation of the neighboring grain and the material. Generally, in all cases, a backstress develops in the twin that resists its growth. For $\mathrm{Mg}$, we show that while increasing the applied load can further drive growth the the increment in applied stress needed to drive twin expansion depends on the neighbor; neighboring grain orientations that are well suited to activate harder slip systems hinder twin growth more than those oriented to activate the easier ones (Fig 3a). For Zr, in contrast, the sensitivity to neighboring grain orientation is significantly stronger than in $\mathrm{Mg}$. For some grain orientations, twin growth is possible when the applied stress increases, while in others, twin growth is uncertain as the TRSS only just meets the CRSS value. There are still others for which twin growth does not seem likely regardless of how much the load has increased (Fig $3 b)$.

The calculations involving a pair of parallel and adjacent twin domains show that interactions of their backstress fields cause an increase in the backstress above that of an isolated twin in the same grain with the same neighbors. At least from the perspective of this meso-scale micromechanical calculation, this result suggests that twins are not expected to coalesce since the stress states do not favor growing two separate twins together to form onetwin lamellae. This conclusion may change because atomic-scale processes that may involve a twin coalescence process are not considered. These mechanisms have yet to be revealed and the model used here can be used to calculate the particular forces that might be important in driving them.

These two-twin calculations expose additional differences between $\mathrm{Mg}$ and $\mathrm{Zr}$. In general, for both metals we have found that the repulsive interaction between the two twins persists and increases the backstress on each twin as the two twins draw closer. However, the critical spacing above which the backstress is no longer enhanced from that of a single isolated twin is less for $\mathrm{Zr}$ than $\mathrm{Mg}$. The neighboring grain has less influence on the critical spacing than the material. This comparison indicates that it is easier in $\mathrm{Zr}$ than $\mathrm{Mg}$ to grow more closely spaced twins. These findings are consistent with the experimental observation that on average more twins per grain form in $\mathrm{Zr}$ than in $\mathrm{Mg}$ for the same grain size [13-14]. 
It is worth pointing out that in all calculations performed here, the orientation of the parent grain and its twin (or twins) and loading state were fixed. The differences in twin growth and two-twin interactions between $\mathrm{Zr}$ and $\mathrm{Mg}$ exposed by the calculation arise due to neighbor and material effects. They would, therefore, not be captured by a Schmid factor analysis or other similar analyses based on average stress states or properties of the parent grain.

Effects of elastic and plastic anisotropy: The twin domain is an inhomogeneity differing in crystallographic orientation from that of its parent and neighboring grains and inducing localized shear. The outcomes of the present analysis are largely due to the local stress fields that are generated due to the introduction of a twin domain (or domains). The intensity and extent of these twin fields differ in $\mathrm{Mg}$ and $\mathrm{Zr}$, largely because of differences in their anisotropic elastic and plastic properties. Table 1 compares the elastic properties and those of the predominant crystallographic slip families of $\mathrm{Mg}$ and $\mathrm{Zr}$ used in simulation. While both $\mathrm{Zr}$ and $\mathrm{Mg}$ are elastically and plastically anisotropic, $\mathrm{Zr}$ is more so in both respects than $\mathrm{Mg}$. The anisotropy means that the elastic and plastic responses of a twin, the surrounding matrix and a neighboring grain will be different in $\mathrm{Zr}$ and in $\mathrm{Mg}$.

The effects of anisotropy are first described conceptually with use of Fig. 8. For the parent grain orientation and loading state considered here, the matrix material surrounding the twin will be geometrically harder than the twin. For an isotropic material the matrix and twin would exhibit the same elastic and plastic response, and the plastic strain field induced by the twin would extend a certain amount into the matrix, as illustrated in Fig. 8. However, neither $\mathrm{Mg}$ nor $\mathrm{Zr}$ is isotropic, and thus the elastic and plastic response of the matrix will be harder than that of the twin. The plastic zone will not be as extended as in the case of the isotropic material (See Fig. 8). Because $\mathrm{Zr}$ is more anisotropic elastically and plastically, the matrix response will be even harder and hence the plastic zone will be even smaller in $\mathrm{Zr}$ than $\mathrm{Mg}$.

In our calculations for $\mathrm{Mg}$ and $\mathrm{Zr}$ many variables differed, which can obscure support of the above explanation. Each metal was modeled with its particular intrinsic material properties; for instance, we neither considered the same characteristic twin shear nor the same slip systems in our analysis. Thus, to numerically demonstrate the effects that elastic and plastic anisotropy have on twinning, we repeat the simulations for two hypothetical $\mathrm{Mg}$ materials: one in which $\mathrm{Mg}$ is elastically anisotropic like $\mathrm{Zr}$, but retains its plastic properties and another in which it retains its elastic properties but adopts plastically anisotropic slip like 
Zr. For the first, we changed the elastic constants $\mathrm{C}_{13}$ and $\mathrm{C}_{44}$ from 21.7 to 11.0 and 16.39 to 10.39, respectively. The resulting elastic anisotropic indices are 1.94, 1.76 and 2.57, which makes it elastically more anisotropic than $\mathrm{Mg}$ (anisotropy indices: 0.98, 1.11 and 1.21). For the second case, the CRSS value of the pyramidal <c+a> slip mode has been increased from 86.2 $\mathrm{MPa}$ to $186.0 \mathrm{MPa}$ and basal <a> slip has been removed. This altered Mg material is plastically more anisotropic than actual $\mathrm{Mg}$ but plastically similar to $\mathrm{Zr}$.

Fig. 9 compares the difference between $S_{a v e}$ for the twin pair and $S_{a v e, 0}$ for the isolated twin as a function of $s$ for three materials: actual $\mathrm{Mg}$, elastically anisotropic $\mathrm{Mg}$ and plastically anisotropic $\mathrm{Mg}$. The calculations show that, like actual $\mathrm{Mg}$, the presence of parallel twins increases the twin backstress compared to the isolated case for the elastically anisotropic and plastically anisotropic $\mathrm{Mg}$ cases. The significant result, however, is that the additional resistive backstress has been reduced when either the elastic or plastic anisotropy is increased compared to actual $\mathrm{Mg}$. The effect is more pronounced for the plastically anisotropic $\mathrm{Mg}$ than elastically anisotropic Mg. As a consequence, for the plastically anisotropic $\mathrm{Mg}$, the optimal twin spacing has reduced to $\sim 19 t$. The increase in plastic (and elastic) anisotropy has reduced the extent of the plastic stress field caused by the twin inhomogeneity onto the matrix region lying inbetween the two twins. This reduction weakens the interaction between the two twins and shortens the twin spacing beyond which they recover their isolated stress states.

Investigation on $\mathrm{Ti}$ : To support the proposed relationship between anisotropy and twin characteristics found for $\mathrm{Mg}$ and $\mathrm{Zr}$, we examine $\mathrm{Ti}$. $\mathrm{Ti}$ is another structural hcp metal that is elastically and plastically anisotropic, but is not entirely like $\mathrm{Zr}$ or $\mathrm{Mg}$. It is similar in stiffness to $\mathrm{Zr}$. Its elastic anisotropic indices are 1.06, 0.75 and 1.21 [51]. Ti has a similarly large characteristic twin shear for $\{1012\}$ twinning of $17.4 \%$. However, compared to $\mathrm{Zr}$, $\mathrm{Ti}$ is plastically softer with more available slip modes. At room temperature, three slip families tend to accommodate the plastic deformation of Ti: prismatic $\langle\mathrm{a}\rangle$, basal $\langle\mathrm{a}\rangle$ and pyramidal $\langle\mathrm{c}+\mathrm{a}\rangle$ slip (see Table 1). While the availability of these three modes may make Ti appear plastically similar to $\mathrm{Mg}$, $\mathrm{Ti}$ is still plastically harder than $\mathrm{Mg}$ since these slip modes have much higher activation stresses compared to that for twinning. Thus, we selected Ti because its natural elastic and plastic properties appeared to lie, roughly speaking, "between” Mg and Zr.

As before, we calculate $S_{T B}$ at the TB in the case of an isolated twin with different neighboring grain orientations. Fig. 10 shows the strain evolution of the ratio between $S_{T B}$ and CRSS. The $S_{T B}$ ratio is negative and with increasing strain, it increases for all cases of grain 
neighbor orientation. In most cases, except two of them, the $S_{T B}$ is able to exceed the CRSS suggesting that further expansion is possible. The ability for the applied strain to further twin growth in Ti exhibits some sensitivity to neighboring grain orientation, more so than $\mathrm{Mg}$ but less so than Zr. As mentioned, Ti is plastically softer and less anisotropic than Zr. Therefore, compared to $\mathrm{Zr}$, the values of the backstresses in $\mathrm{Ti}$ would be smaller and less sensitive to neighboring grain orientation.

Next, we carry out simulations with two identical, adjacent and parallel twins with separation $s$. Figs. 11(a)-(c) compares the TRSS distribution for an isolated twin and for twotwins with the spacing of $2 t$ and 20t. These stress fields are qualitatively similar to those calculated for Zr. Fig. 11(d) presents the difference between $S_{a v e}$ for two twins and $S_{a v e, 0}$ for the isolated twin as a function of $s$. In general, the value of the backstress in the twin domain is higher for the pair of interacting twins compared to that of a single twin. The critical spacing at which the $S_{\text {ave }}$ recovers $S_{\text {ave, },}$ is $\sim 15 t$, larger than that for $\mathrm{Zr}$, but smaller than that for $\mathrm{Mg}$ for the same neighbor orientation.

The analysis in Figs. 10 and 11 imply that, compared to $\mathrm{Mg},\{1012\}$ twins in Ti will tend not to grow as thick and the number of twins per grain will be larger. This tendency agrees with the notion discussed earlier. Since Ti is elastically and plastically more anisotropic than $\mathrm{Mg}$, the difference in the elastic and plastic properties of the matrix domain in-between the two twins is greater. For the parent orientation simulated, the matrix is stiffer than the twin for accommodating shear parallel to the twin plane, and the plastic strain fields induced by twins are less extended in $\mathrm{Ti}$ than in $\mathrm{Mg}$. Consequently, the interaction between two twins would be weaker and so will be the critical spacing to lower the backstresses.

Elastic energy for different HCP materials: So far, we have discussed the twinning characteristics of HCP $\mathrm{Mg}, \mathrm{Zr}$ and Ti using the TRSS as the driving stress for twinning. The elastic energy is another measure through which we can understand differences in twinning characteristics among different HCP materials. To this end, we compare the elastic energies in the twin lamellae and in parent grain for an isolated twin $\left(\mathrm{E}_{0}\right)$ with those for two parallel twins (E). Figure 12 present the relative difference in $\mathrm{E}$ and $\mathrm{E}_{0}$ for $\mathrm{Mg}, \mathrm{Ti}$, and $\mathrm{Zr}$. Because two twins doubles the volume fraction of heterogeneity than one twin, we expect the elastic energy to increase when a second twin forms. However, we see that among the three metals, $\mathrm{Mg}$ experiences the greatest penalty when a second twin develops. This result suggests that the accommodation of two (multiple) twins is more energetically favorable in $\mathrm{Zr}$ and $\mathrm{Ti}$ compared 
to $\mathrm{Mg}$. The penalty, however, decreases with twin spacing, implying that second twin formation is preferred away from the first twin.

\section{Conclusions}

We employ a recently developed 3D elasto-visco-plastic Fast Fourier Transform model to study the driving forces that would be responsible for the growth of an isolated twin lamella and a pair of twin lamellae. The calculations are applied to $\{1012\}$ twin lamellae in $\mathrm{Mg}, \mathrm{Zr}$, and Ti using CRSS's for slip corresponding to temperatures at which twin activity is relevant, namely: $300 \mathrm{~K}, 76 \mathrm{~K}$ and $300 \mathrm{~K}$, respectively. We investigate the effects of neighbors and their elastic and plastic anisotropy differences. Since the latter are represented by variations in the ratios of CRSS's - which change with temperature in the actual materials - to some extent the conclusions can be applied to temperature dependence of the effects discussed in this paper. In simulation, the twins are contained in one grain and bounded by grain boundaries formed by neighboring grains differing in crystallographic orientation. The unit cell is subjected to inplane compression, which is an arbitrary choice to get a positive resolved shear stress on the twin plane. Any other arbitrary applied stress would have worked, provided that it induced the same resolved shear stress on the twin plane. The orientation of the parent grain is fixed and only the neighboring grains orientation is changed. Because the variation in twin local stresses mainly depends on the relative mis-orientation between the parent and the neighboring grains, not on the absolute orientations. And also the number of orientations for the neighboring grains studied here is not extensive. Quantitative differences would be expected if more neighboring grain orientations were considered, and also if the applied stress is different than the in-plane compression. However these calculations provide the following useful insight. First, with all else being the same, the backstresses that develop in the twin in $\mathrm{Zr}$ are more sensitive to the neighboring grain orientation. Second, the values of backstress in $\mathrm{Zr}$ are much larger compared to its CRSS for twinning than those in $\mathrm{Mg}$.

The simulations on a single twin lamella reveal that driving forces for twin growth in a parent grain vary as a function of the orientation of the neighboring grain and the material. Generally, a backstress develops in the twin that resists its growth, a result that intuitively would suggest that the load needs to be increased in order to further drive growth. For $\mathrm{Mg}, \mathrm{Ti}$ and $\mathrm{Zr}$ alike, the analysis finds that the increment in applied stress needed to drive twin expansion depends on the grain neighbor. However, the sensitivity to neighboring grain 
orientation grows stronger when going from $\mathrm{Mg}$, to $\mathrm{Ti}$, and to $\mathrm{Zr}$, in this order. $\mathrm{In} \mathrm{Zr}$, and to some extent in $\mathrm{Ti}$ as well, twin growth does not seem likely for some grain orientations, regardless of how much the load has increased. These differences arise in spite of the fact that the parent, twin, and loading orientation were the same in all cases.

Simulations involving a pair of parallel and adjacent twins reveal that their interacting stress fields cause the resistive backstress on each twin to be higher than if each twin was isolated. The enhanced backstress increases in magnitude as the two twins draw closer. In the analysis, we identify a critical spacing above which the backstress is no longer affected by the presence of the second twin. We find that the critical spacing is lower for $\mathrm{Zr}$ than for $\mathrm{Ti}$, and lower for $\mathrm{Ti}$ than for $\mathrm{Mg}$.

The findings could explain why the observed correlation between twin Schmid factor and twin thickness is strong in $\mathrm{Mg}$, but not in $\mathrm{Zr}$ [13-14]. They also imply that it is easier in $\mathrm{Zr}$ than $\mathrm{Mg}$ to grow more twins per grain and more closely spaced twins. This result is consistent with the observation that on average more (and narrower) twins per grain form in $\mathrm{Zr}$ than in $\mathrm{Mg}$ for the same grain size [13-14]. We argue here that the predicted differences between $\mathrm{Mg}$ and $\mathrm{Zr}$ are a consequence of their differing degree of elastic and plastic anisotropy. We support this postulate via additional calculations done on $\mathrm{Ti}$.

\section{Acknowledgements}

This work was entirely funded by US Department of Energy, Office of Basic Energy Sciences (OBES) FWP-06SCPE401.

\section{References}

[1]. A. Akhtar and A. Teghtsoonian, Acta Metall 19 (1971) 655-663

[2]. P.G. Partridge, "The crystallography and deformation modes of hexagonal closepacked metals", Metallurgical Reviews 12 (1967) 169-194

[3]. R.E. Reed-Hill, "Role of deformation twinning in the plastic deformation of a polycrystalline anisotropic material", in 'Deformation Twinning', R.E. Reed-Hill, J.P. Hirth and H.C. Rogers eds., Gordon and Breach, New York (1964) 295-320.

[4]. M.H. Yoo, "Slip, twinning and fracture in Hexagonal Close Packed metals", Met. Trans. 124 (1981) 409

[5].M.H. Yoo, S.R. Agnew, J.R. Morris and K.M. Ho, "Non-basal slip systems in HCP metals and alloys: source mechanisms", Mater Sci Eng A319-321 (2001) 87-92

[6].G.C. Kaschner, C.N. Tomé, I.J. Beyerlein, S.C. Vogel, D.W. Brown, R.J. McCabe, "Role of twinning in the hardening response of $\mathrm{Zr}$ during temperature reloads", Acta Mater 54 (2006) 2887-96

[7].G. Proust, C.N. Tomé and G.C. Kaschner, "Modeling texture, twinning and hardening evolution during deformation of hexagonal materials", Acta Mater 55 (2007) 2137-48 
[8]. C.N. Tomé, P.J. Maudlin, R.A. Lebensohn, G.C. Kaschner, "Mechanical response of zirconium. Part I: Derivation of a polycrystal constitutive law and Finite Element analysis", Acta Mater 49 (2001) 3085-96

[9].J.F. Bingert, T.A. Mason, G.C. Kaschner, P.J. Maudlin, G.T. Gray III, “Deformation twinning in polycrystalline Zr: insights from Electron Back Scattered Diffraction characterization", Metall Mater Trans 33A (2002) 955-963

[10]. Y.B. Chun, S.H. Yu, S.L. Semiatin, S.K. Hwang, "Effect of deformation twinning on microstructure and texture evolution during cold rolling of CP-titanium", Mater Sci Eng A398 (2005) 209-219

[11]. M.D. Nave, M.R. Barnett, "Microstructures and textures of pure magnesium deformed in plane-strain compression", Scr Mater 51 (2004) 881-885

[12]. I.J. Beyerlein, X. Zhang, A. Misra, "Growth twins and deformation twins in metals", Annual Reviews in Materials Research 44 (2014) 329-363

[13]. I.J. Beyerlein, L. Capolungo, P.E. Marshall, R.J. McCabe, C.N. Tomé, "Statistical analyses of deformation twinning in magnesium", Philos Magazine 90 (2010a) 2161-90

[14]. L. Capolungo, P.E. Marshall, R.J. McCabe, I.J. Beyerlein, C.N. Tomé, "Nucleation and propagation of twins in Zr: a statistical study", Acta Mater 57 (2009) 6047-56

[15]. S.G. Song, G.T. Gray III, "Structural interpretation of the nucleation and growth of deformation twins in $\mathrm{Zr}$ and $\mathrm{Ti}$ - I: Application to the coincident site lattice theory to twinning problems in HCP structures", Acta Metall Mater 43 (1995a) 2325-37

[16]. J.J. Jonas, S. Mu, T. Al-Samman, G. Gottstein, L. Jiang, E. Martin, "The role of strain accommodation during the variant selection of primary twins in Mg", Acta Mater. 59 (2011) 2046-56

[17]. A. Khosravani, D.T. Fullwood, B.L. Adams, T.M. Rampton, M.P. Miles, R.K. Mishra, "Nucleation and propagation of $\{10-12\}$ twins in AZ31 magnesium alloy", Acta mater 100 (2015) 202-214

[18]. X. Li, Y.L. Duan, G.F. Xu, X.Y. Peng, C. Dai, L.G. Zhang, Z. Li, “EBSD characterization of twinning in coled rolled pure Ti", Mater. Charact 84 (2013) 4147

[19]. T.A. Mason, J.F. Bingert, G.C. Kaschner, S.I. Wright, R.J. Larsen, "Advances in deformation twin characterization using Electron Back Scattered Diffraction data", Metall Mater Trans 33A (2002) 949-954

[20]. H. Qin, J. J. Jonas, H. Yu, N. Brodusch, R. Gauvin and X. Zhang, "Initial and accommodation of primary twins in high purity titanium", Acta Mater 71 (2014) 293-305

[21]. I.J. Beyerlein, C.N. Tomé, "A probabilistic twin nucleation model for HCP polycrystalline metals", Proc Roy Soc of London A466 (2010b) 2517-44

[22]. M.R. Barnett, M.D. Nave, A. Ghaderi, "Yield point elongation due to twinning in a magnesium alloy", Acta Mater 60 (2012) 1433-1443

[23]. M.R. Barnett, A. Ghaderi, J. Quinta da Fonseca, J.D. Robson, "Influence of orientation on twin nucleation and growth at low strains in a magnesium alloy", Acta Mater 80 (2014) 380-391

[24]. A. Ghaderi and M.R. Barnett, "Sensitivity of deformation twinning to grain size in titanium and magnesium", Acta Mater 59 (2011) 7824-7839

[25]. W. Tirry, S. Bouvier, N. Benmhenni, W. Hammami, A.M. Habraken, F. Coghe, D. Schryvers, L. Rabet, "Twinning in pure Ti subjected to monotonic simple shear deformation", Mater Characterization 72 (2012) 24-36

[26]. N. Ecob, B. Ralph, "The effect of grain size on deformation twinning in a textured zinc alloy", J Mater Sci 18 (1983) 2419-29 
[27]. A. Jain, O. Duygulu, D.W. Brown, C.N. Tomé, S.R. Agnew, "Grain size effects on the tensile properties and deformation mechanisms of a magnesium alloy AZ31B sheet", Mater Sci Eng A486 (2008) 545-555

[28]. K.V. Mani Krishna, D.G. Leo Prakash, G. Timar, A. Fitzner, D. Srivastava, N. Saibada, J. Quinta da Fonseca, G.K. Dey, M. Preuss, "The effect of loading direction and Sn alloying on the deformation of Zr: An in-situ neutron diffraction study", Mater Sci Eng A650 (2016) 497-509

[29]. V.A. Moskalenko, V.I. Startsev, V.N. Kovaleva, "Low temperature peculiarrties of plastic deformation in titanium and its alloys", Cryogenics 20 (1980) 503-508

[30]. S.R. Niezgoda, A.K. Kanjarla, I.J. Beyerlein, C.N. Tomé, "Stochastic model of twin nucleation in polycrystals: an application to hexagonal close packed metals", Int J Plast 56 (2014) 119-138

[31]. W-P Deng, Z-F Gao, X-W Li, "Temperature and strain rate dependence of deformation microstructures of Az31 magnesium alloy under uniaxial tension", Advanced Materials Research 217-218 (2011) 93-96

[32]. A.M. Garde, R.E. Reed-Hill, "The importance of mechanical twinning in the stress-strain behavior of swaged high purtity fine grained titanium below $424^{\circ} \mathrm{K}$ ", Metall Trans 2 (1971) 2885-2888

[33]. A. Ghaderi F. Siska, M.R. Barnett, "Influence of temperature and plastic relaxation on tensile twinning in a magnesium alloy", Scr Mater 69 (2013) 521-524

[34]. A. Jain, S.R. Agnew, "Modeling the temperature dependent effect of twinning on the behavior of Mg alloy AZ31 sheet", Mater Sci Eng A462 (2007) 29-36

[35]. A.S. Khan, A. Pandey, T. Gnäupel-Herold, R.J. Mishra, "Mechanical response and texture evolution of AZ31 alloy at large strains for different strain rates and temperatures", Int J Plast 27 (2011) 688-706

[36]. P. Klimanek, A. Potzsch, "Mircostructure evolution under compressive plastic deformation of magnesium at different temperatures and strain rates", Mater Sci Eng A324 (2002) 145-150

[37]. R.J. McCabe, E.K. Cerreta, A. Misra, G.C. Kaschner, C.N. Tomé, “Effects of texture, temperature and strain on the deformation modes of zirconium", Philos Mag A86 (2006) 3595-3611

[38]. M.R. Barnett, Z. Keshavarz, A.G. Beer, D. Atwell, "Influence of grain size on the compressive deformation of wrought Mg-3Al-1Zn “, Acta Mater 52 (2004b) 5093-5103

[39]. S.G. Hong, S.H. Park, C.S. Lee, "Role of $\{10-12\}$ twinning characteristics in the deformation behavior of a polycrystalline magnesium alloy", Acta Mater 58 (2010) 5873-85

[40]. S. Nemat-Nasser, W.G. Guo, J.Y. Cheng, "Mechanical properties and deformation mechanisms of a commercially pure titanium", Acta mater 47 (1999) 3705-20

[41]. A.A. Salem, S.R. Kalidindi, R.D. Doherty, "Strain hardening of titanium: role of deformation twinning", Acta Mater 51 (2003) 4225-37

[42]. M. Arul Kumar, A.K. Kanjarla, S.R. Niezgoda, R.A. Lebensohn, C.N. Tomé, "Numerical study of the stress state of a deformation twin in magnesium", Acta Mater 84 (2015) 349-358

[43]. H. Moulinec, P.Suquet, "A numerical method for computing the overall response of nonlinear composites with complex microstructures", Comput Methods Appl Mech Engg 157 (1998) 69-94

[44]. R.A. Lebensohn, "N-site modeling of a 3D viscoplastic polycrystal using Fast Fourier Transform", Acta Mater 49 (2001) 2723-37 
[45]. R. Brenner, R.A. Lebensohn and O.Castelnau, "Elastic anisotropy and yield surface estimates of polycrystals", Int. J. Solids Struct 46 (2009) 3018-3026

[46]. P. Eisenlohr, M. Diehl, R.A. Lebensohn, F. Roters, "A spectral method solution to crystal elasto-viscoplasticity at finite strains", Int J Plast 46 (2013) 37-53

[47]. A.K. Kanjarla, R.A. Lebensohn, L. Balogh, C.N. Tomé, "Study of internal lattice strain distributions in stainless steel using a full-field elasto-viscoplastic formulation based on Fast Fourier Transforms", Acta Mater 60 (2012) 3094-3106

[48]. R.A. Lebensohn, R. Brenner, O. Castelnau, A.D. Rollett, "Orientation image-based micromechanical modelling of subgrain texture evolution in polycrystalline copper", Acta Mater 56 (2008) 3914-26

[49]. R.A. Lebensohn, M.I. Idiart, P. Ponte Castaneda, P.G. Vincent, "Dilatational viscoplasticity of polycrystalline solids with intergranular cavities", Philos Mag. 91 (2011) 3038-3067

[50]. R.A. Lebensohn, A.K. Kanjarla, P. Eisenlohr, "An elasto-visco-plastic formulation based on Fast Fourier transforms for the prediction of micromechanical fields in polycrystalline materials", Int J of Plasticity 32-33 (2012) 59-69

[51]. U.F. Kocks, C.N. Tomé, H.R. Wenk, "Texture and Anisotropy - Preferred Orientations in Polycrystals and their Effect on Materials Properties", Cambridge University Press (1998), 2nd edition (2000)

[52]. G. Simmons and H. Wang, "Single crystal elastic constants and calculated aggregate properties: A Handbook", The MIT press (1971)

[53]. I.J. Beyerlein, R.J. McCabe, C.N. Tomé, "Effect of microstructure on the nucleation of deformation twins in polycrystalline high-purity magnesium: a multiscale modeling study", J Mech Phys Solids 59 (2011) 988-1003

[54]. Knezevic, I.J. Beyerlein, T. Nizolek, N.A. Mara, T. M. Pollock, “Anomalous basal slip activity in zirconium under high strain deformation", Mater. Res. Lett. 1 (2013) 133-140

[55]. M. Knezevic, M. Zecevic, I.J. Beyerlein, J.F. Bingert, R.J. McCabe, "Strain rate and temperature effects on the selection of primary and secondary slip and twinning systems in HCP Zr", Acta Mater 88 (2015) 55-73

[56]. L. Wang, R.I. Barabash, Y. Yang, T.R. Bieler, M.A. Crimp, P. Eisenlohr, W. Liu, G.E. Ice, "Experimental characterization and crystal plasticity modeling of heterogeneous deformation in polycrystalline $\alpha$-Ti”, Metall Mater Trans 42A (2011) 626

[57]. X. Wu, S.R. Kalidindi, C.T. Necker, A.A. Salem, "Prediction of crystallographic texture evolution and anisotropic stress-strain curves during large plastic strains in high purity $\alpha$-Ti using a Taylor type crystal plasticity model", Acta Mater 55 (2007) 423-432

[58]. J.W. Christian, S. Mahajan, "Deformation twinning", Prog. Mater Sci 39 (1995) 1157

[59]. J. Wang, S.K. Yadav, J.P. Hirth, C.N. Tomé, I.J. Beyerlein, "Pure-shuffle nucleation of deformation twins in HCP metals", Mats Res Letters 1 (2013a) 126-132

[60]. Y.J. Li, Y.J. Chen, J.C. Walmsley, R.H. Mathinsen, S. Dumoulin. H.J. Roven, “Facted interfacial sturture of $\{1011\}$ twins in Ti formed during equal channel angular pressing", Scripta Mater. 62 (2010) 443-446

[61]. A. Ostapovets and P. Molnár, "Twinning disconnections and basal-prismatic twin boundary in magnesium”, Modelling Simul. Mater. Sci. Engg. 22 (2014) 025015

[62]. A. Ostapovets, P. Molnár, R. Groger, "On basal-prismatic twinning interfaces in magnesium”, Mater. Sci. Eng., 63 (2014) 012134

[63]. S.G. Song, G.T. Gray III, "Structural interpretation of the nucleation and growth of deformation twins in $\mathrm{Zr}$ and Ti - II: TEM study of twin morphology and defect 
reactions during twinning", Acta metall Mater 43 (1995b) 2339-50

[64]. Q. Sun, X.Y. Zhang, R.S. Yin, Y. Ren, L. Tan, "Structutral characterization of $\{10-$ 13\} twin boundaries in deformed cobalt", Scripta Mater 108 (2015) 109-112

[65]. J. Tu, X. Zhang, J. Wang, Q. Sun, Q. Liu, C.N. Tomé, "Structural characterization of \{10-12\} twin boundaries in Cobalt", Appl. Phys. Lett. 103 (2013) 051903, 1-4

[66]. J. Wang, L. Liu, C.N. Tomé, S.X. Mao, S.K. Gong, "Twinning and de-twinning via glide and climb of twinning dislocations along serrated coherent twin boundaries in HCP metals", Mater. Res. Lett. 1 (2013b) 81-88

[67]. J. Wang, Q. Yu, Y. Jiang, I. J. Beyerlein, “Twinning-associated boundaries in hexagonal-close-packed metals", J. Microsc. 66 (2014b) 95-101

[68]. W.A.T. Clark, R.H. Wagoner, Z.Y.Shen, T.C. Lee, I.M. Robertson, H.K. Birnbaun, "On the criteria for slip transmission across interfaces in piloycrsytals", Scripta Metall Mater 26 (1992) 203-206

[69]. H. Abdolvand and M.R. Daymond, "Internal strain and texture development during twinning: comparing neutron diffraction measurements with crystal plasticity finite-element approaches", Acta Mater 60 (2012) 2240-48

[70]. H. Abdolvand and M.R. Daymond, "Multi-scale modeling and experimental study of twin inception and propagation in HCP materials using a crystal plasticity finite-element approach - Part II: local behavior”, J Mech Phys Solids 61 (2013) 803-818

[71]. C.C. Aydiner, J.V. Bernier, B. Clausen, U. Lienert, C.N. Tomé, D.W. Brown, "Evolution of stress in individual grains and twins in a magnesium alloy aggregate", Phys Rev B80 (2009) 024113 1-6

[72]. L. Balogh, S.R. Niezgoda, A.K. Kanjarla, D.W. Brown, B. Clausen, W. Liu, C.N. Tomé, "Spatially resolved in-situ strain measurements from an interior twinned grain in bulk polycrystalline AZ31 alloy", Acta Mater. 61 (2013) 3612-20

[73]. T. B. Britton and A. J. Wilkinson, "High resolution electron backscatter diffraction measurements of elastic strain variations in the presence of larger lattice rotations", Ultramicroscopy 114 (2012) 82-95

[74]. S.R. Niezgoda, R.J. McCabe, C.N. Tomé, "Quantification of strain and orientation measurement error in cross-correlation Electron Back Scatter Diffraction in HCP materials", Scripta Mater 67 (2012) 818-821

[75]. M. Ardeljan, R. J. McCabe, I. J. Beyerlein, M. Knezevic, "Explicit incorporation of deformation twins into crystal plasticity finite element models", Computational Methods in Applied Mechanics and Engineering 295 (2015) 396-413. 


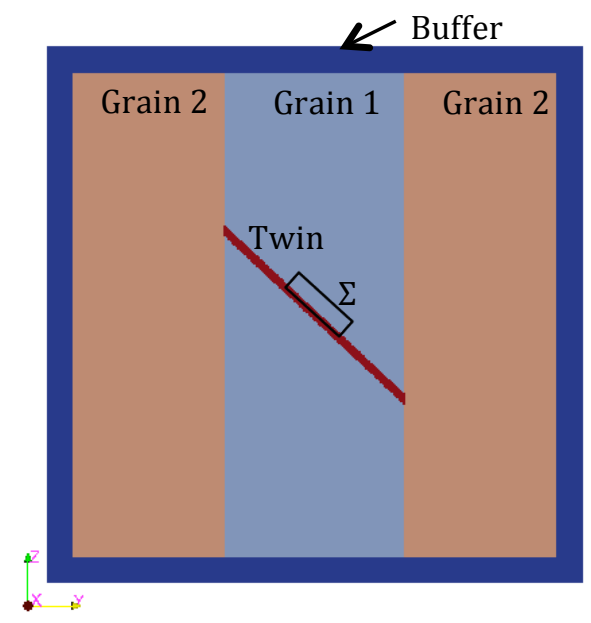

Figure 1: Schematic representation of the simulation tri-crystal unit cell. The twin is embedded in a central grain (grain 1) and the twin front is arrested at the grain boundaries formed by neighboring grains (grain 2). The region denoted as $\Sigma$ represents the 'central' region of the twin boundary with 6 voxels in size, where stresses are averaged (see text for more details).
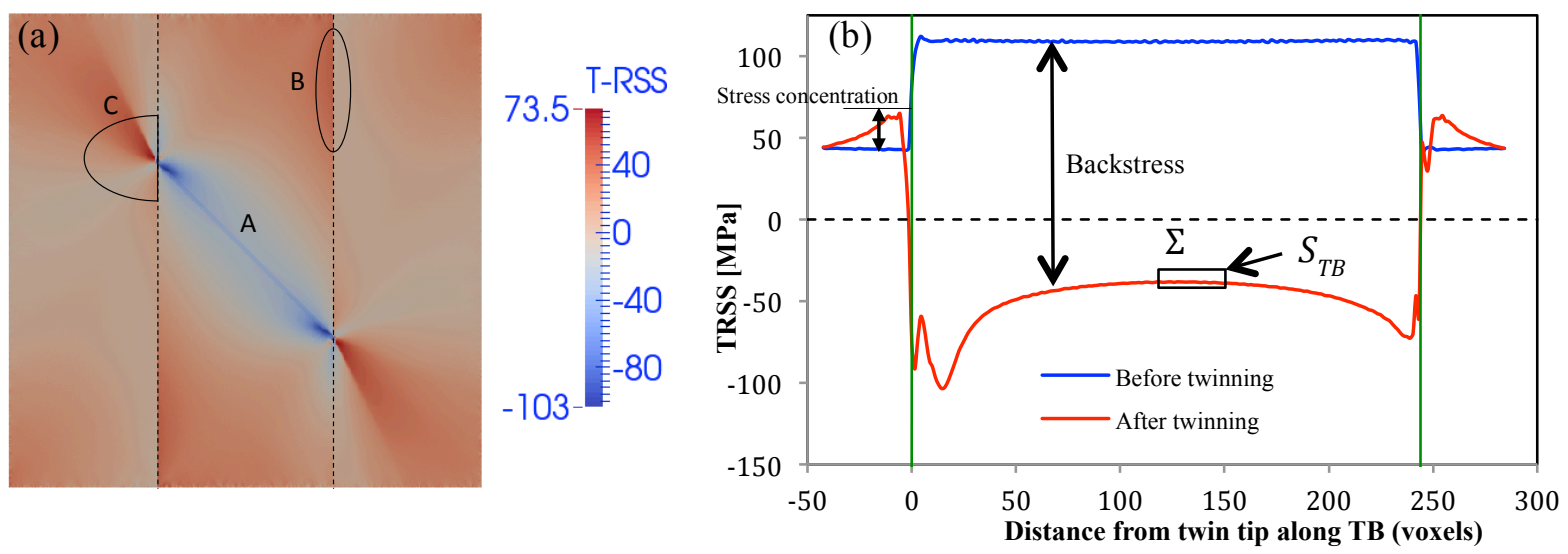

Figure 2: (a) Distribution of TRSS field for $\mathrm{Zr}$ with the central grain orientation $\left(0^{\circ}, 0^{\circ}, 0^{\circ}\right)$ and the neighboring grain orientation $\left(75^{\circ}, 62^{\circ}, 0^{\circ}\right)$. The relevant regions for further twinning processes are marked. (b) TRSS profile along twin top boundary. The two vertical green lines correspond to the position of twin tips. 

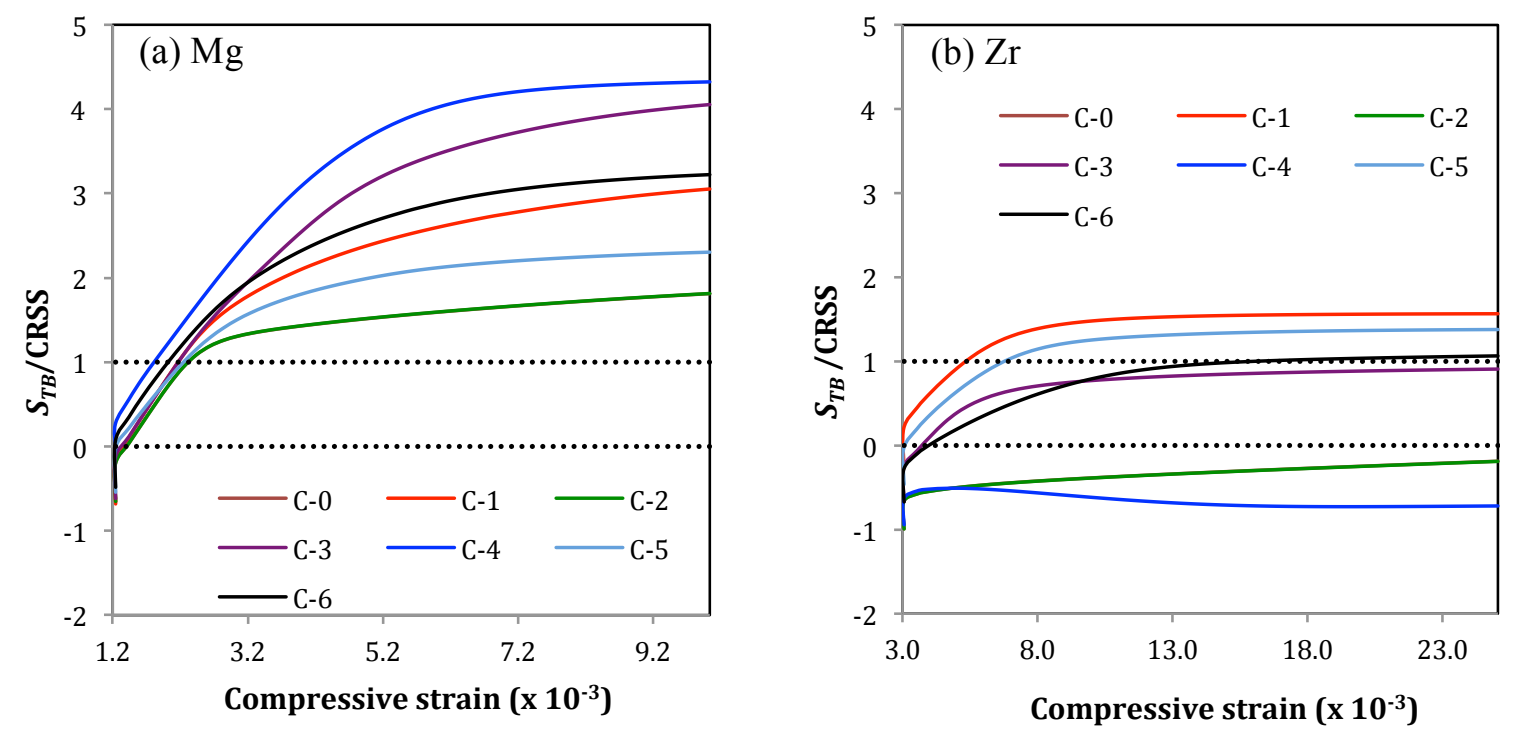

Figure 3: Evolution of the ratio between average TRSS in the region $\Sigma$ in twin boundary center, $S_{T B}$, and CRSS in (a) $\mathrm{Mg}$ and (b) Zr. C-0 to C-6 represent different neighboring grain cases given in Table 1 . The normalization CRSS is $20 \mathrm{MPa}$ for $\mathrm{Mg}$, and $102 \mathrm{MPa}$ for $\mathrm{Zr}$.

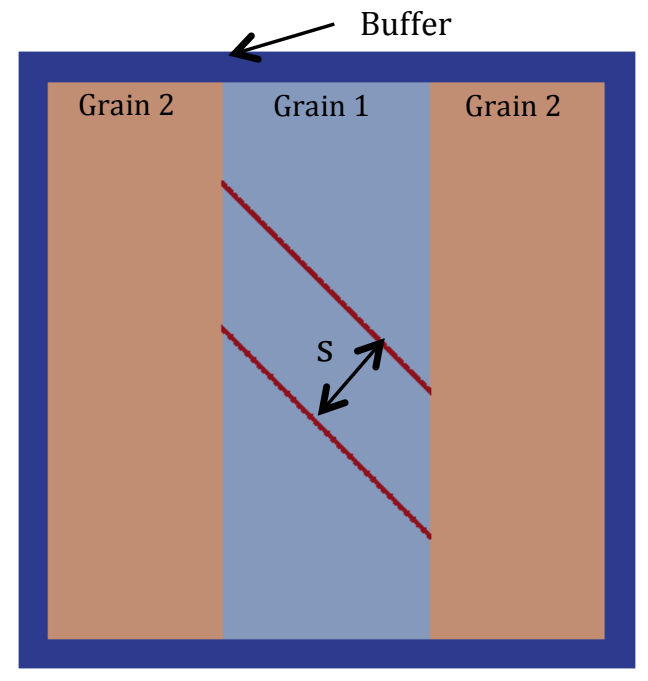

Figure 4: Tri-crystal simulation unit cell with two twins embedded in a central grain (grain 1) with the spacing of $n t, t$ is the twin thickness. Both twins are arrested at the grain boundary between grains 1 and 2. 

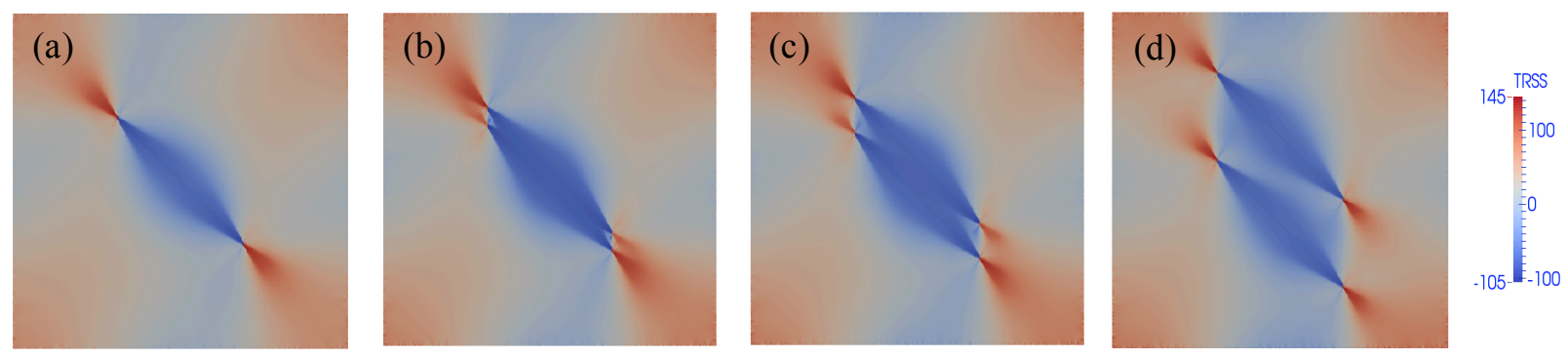

Figure 5: Distribution of twin-plane resolved shear stress (TRSS) after twinning in $\mathrm{Zr}$ for the twin spacing of (a) $\mathbf{0 t}$ (isolated twin), (b) $\mathbf{2 t}$, (c) $\mathbf{8 t}$ and (d) $\mathbf{2 0 t}$; $\mathbf{t}$ is the twin thickness. The neighboring grain orientation is $\left(0^{\circ}, 0^{\circ}\right.$, $\left.0^{\circ}\right)$, i.e., case- 0 .
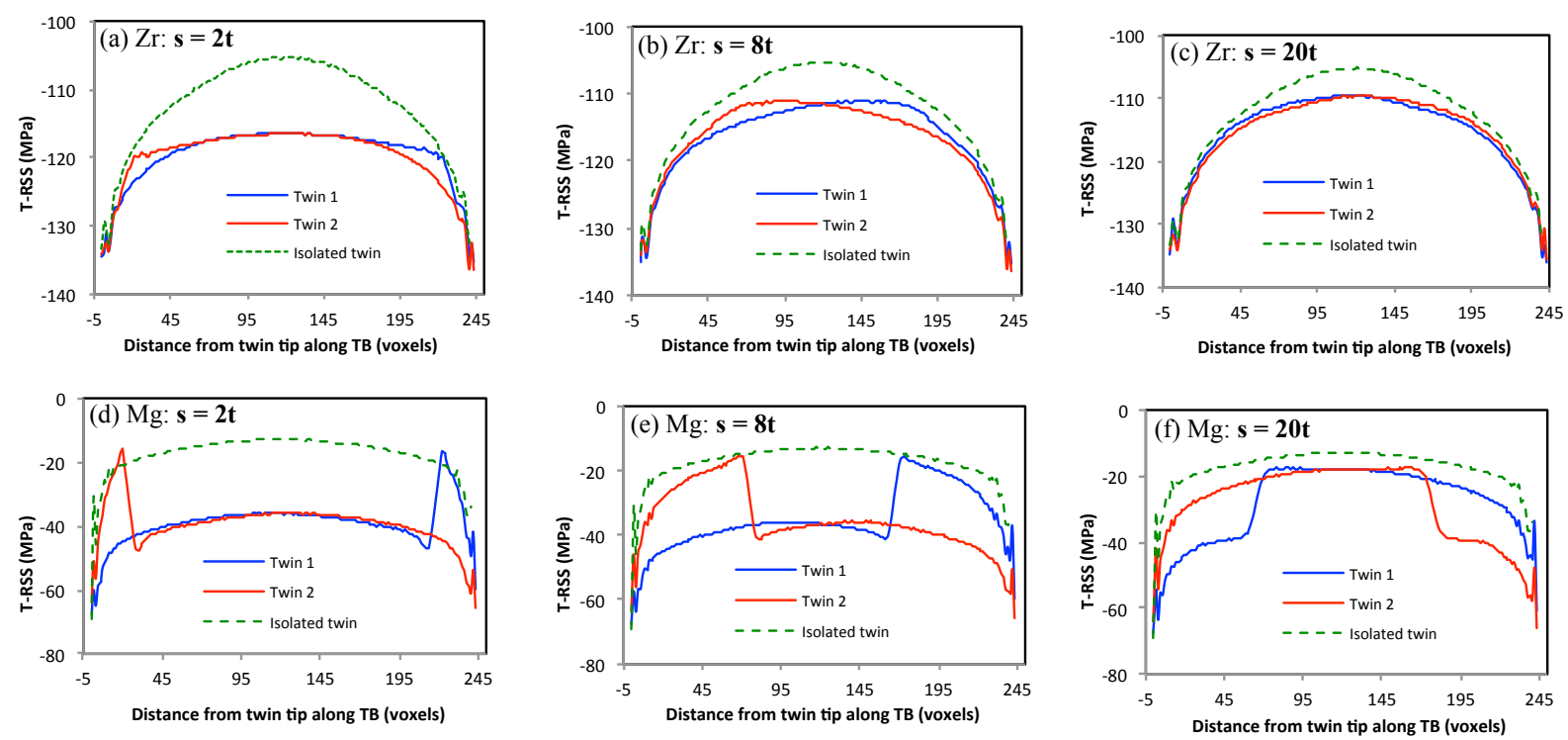

Figure 6: TRSS profile along twin midsection of twins with different spacings, compared with the isolated twin case. The first and second row corresponds to $\mathrm{Mg}$ and $\mathrm{Zr}$. The first, second and third columns correspond to the cases with the spacing of $2 t, 8 t$ and $20 t$, respectively. The neighboring grain orientation is $\left(0^{\circ}, 0^{\circ}, 0^{\circ}\right)$, i.e., case- 0 . 

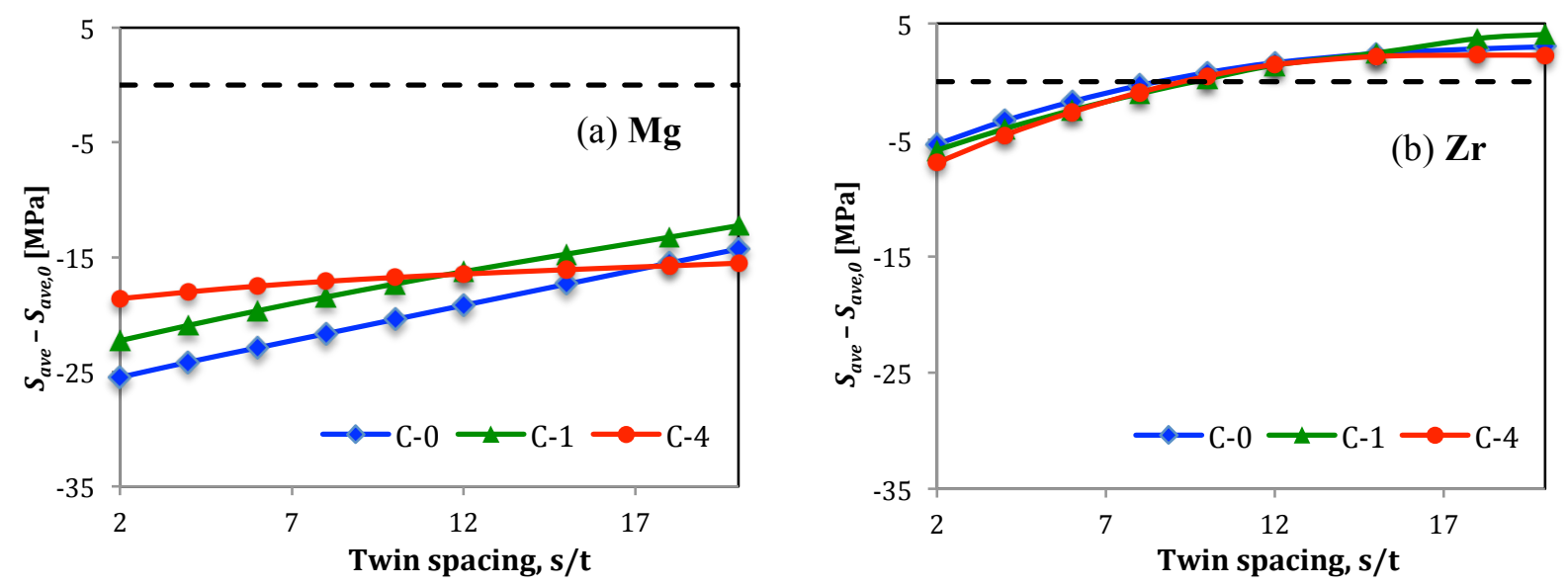

Figure 7. The difference between $\mathrm{S}_{\text {ave }}$ of two-twin case with different twin spacing and $\mathrm{S}_{\mathrm{ave}, 0}$ of an isolated twin in (a) $\mathrm{Mg}$ and (b) $\mathrm{Zr}$. C-0, C-1, and C-4 refer to neighboring grain orientations given in Table 1.

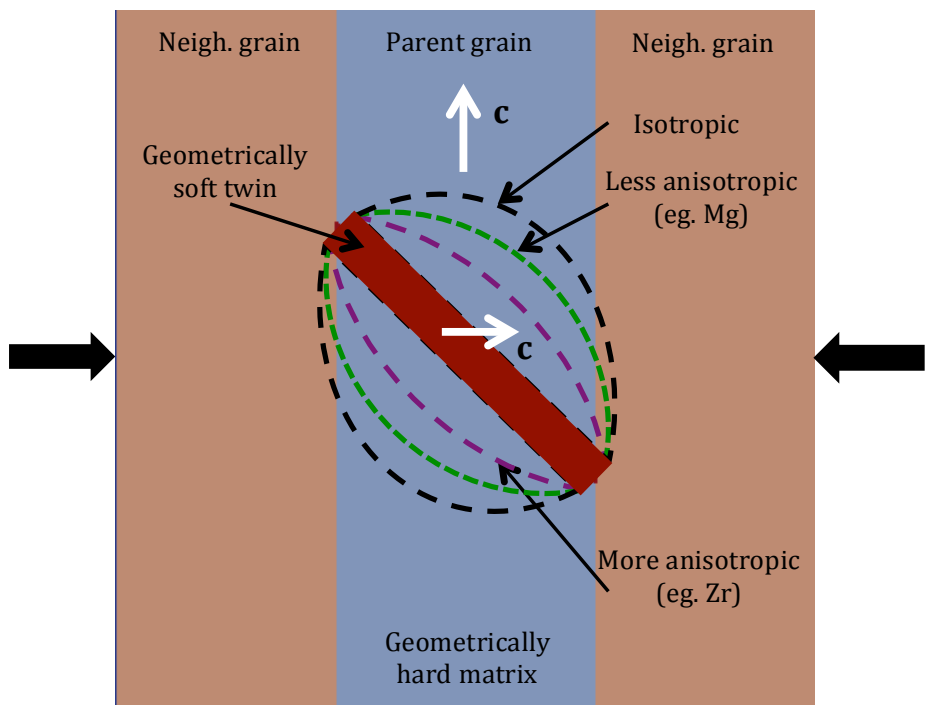

Figure 8: Schematic representation of the twin influencing zone for material with isotropic, less anisotropic (eg. Mg) and more anisotropic (eg. Zr) deformation behavior. 


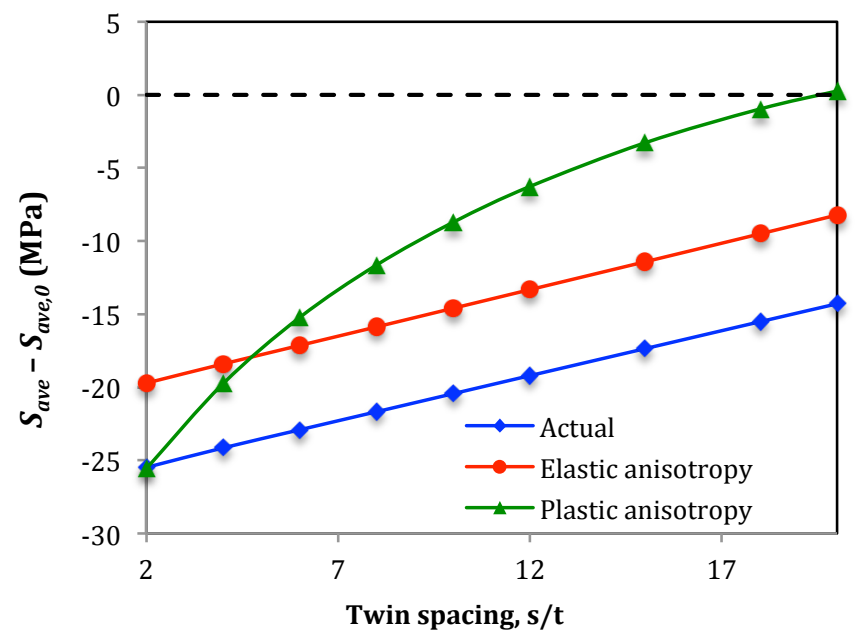

Figure 9. Difference between average TRSS in twin of the two twin case $\left(S_{a v e}\right)$ and the isolated case $\left(S_{\text {ave, } 0}\right)$ for three different material: actual $\mathrm{Mg}$, elastically anisotropic $\mathrm{Mg}$ and plastically anisotropic $\mathrm{Mg}$. The neighboring grain orientation same as the parent grain orientation, i.e., case- 0 .

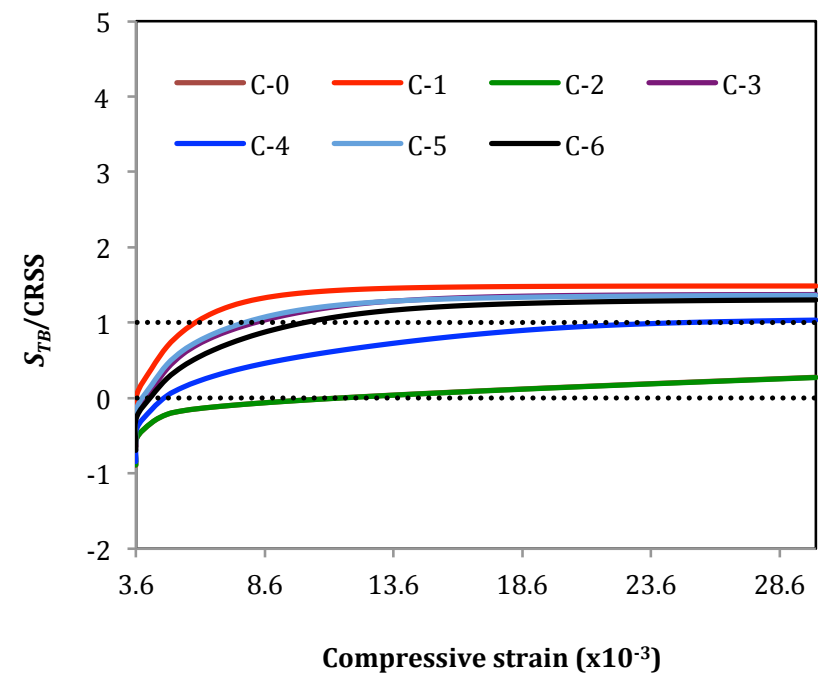

Figure 10. Evolution of the ratio between average TRSS in the TB middle region, $S_{T B}$, marked as $\Sigma$ in Fig. 1, and CRSS for Ti. C-0 to C-6 represent different neighboring grain cases given in Table 1. 


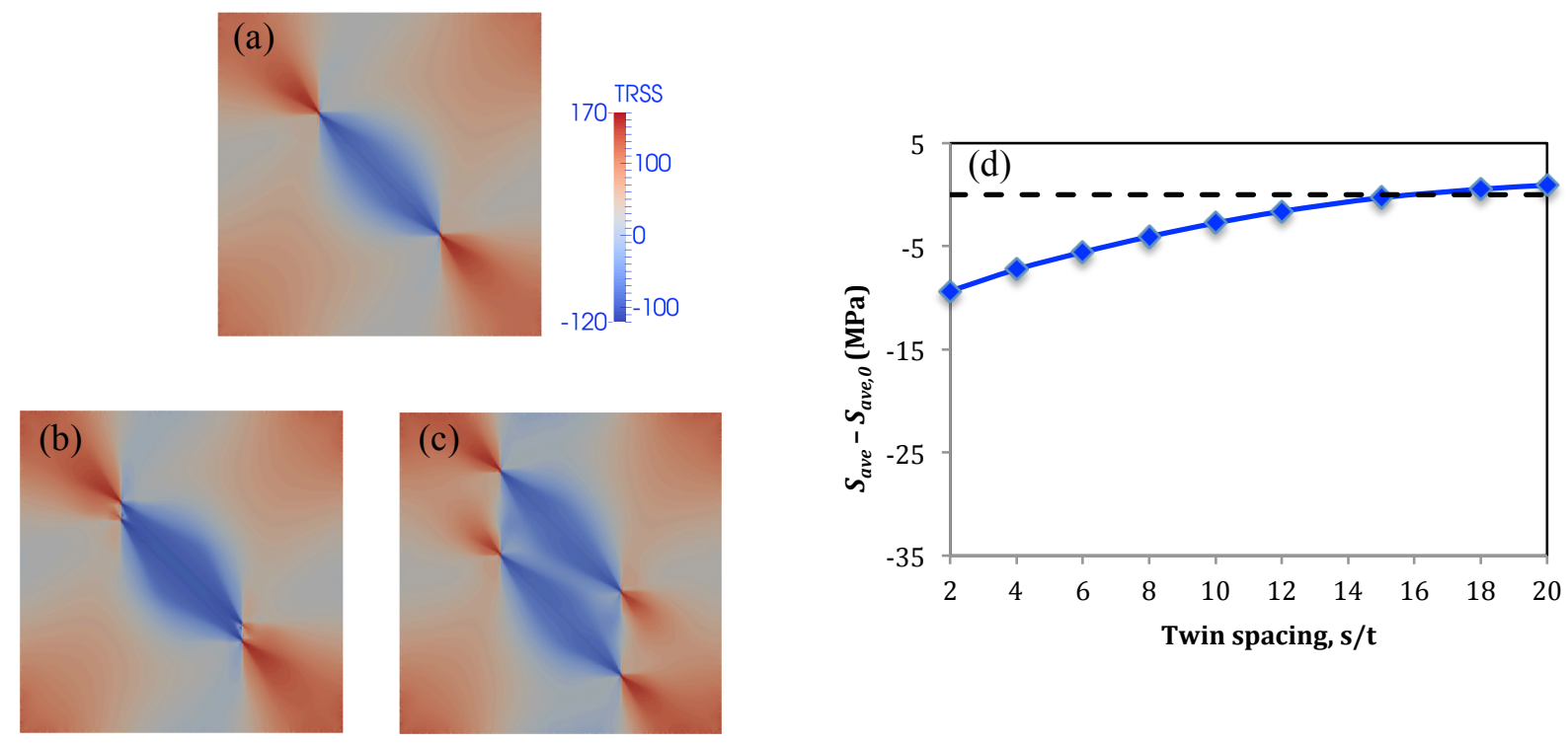

Figure 11: Distribution of TRSS after twinning in Ti for the twin spacing of (a) $\mathbf{0 t}$, (b) $\mathbf{2 t}$ and (c) 20t; $\mathbf{t}$ is the twin thickness. (d) The difference between $\mathrm{S}_{\mathrm{ave}}$ of parallel twin and of $\mathrm{S}_{\mathrm{ave}, 0}$ isolated twin for different twin spacing. The neighboring grain orientation is $\left(0^{\circ}, 0^{\circ}, 0^{\circ}\right)$, i.e., case 0 .

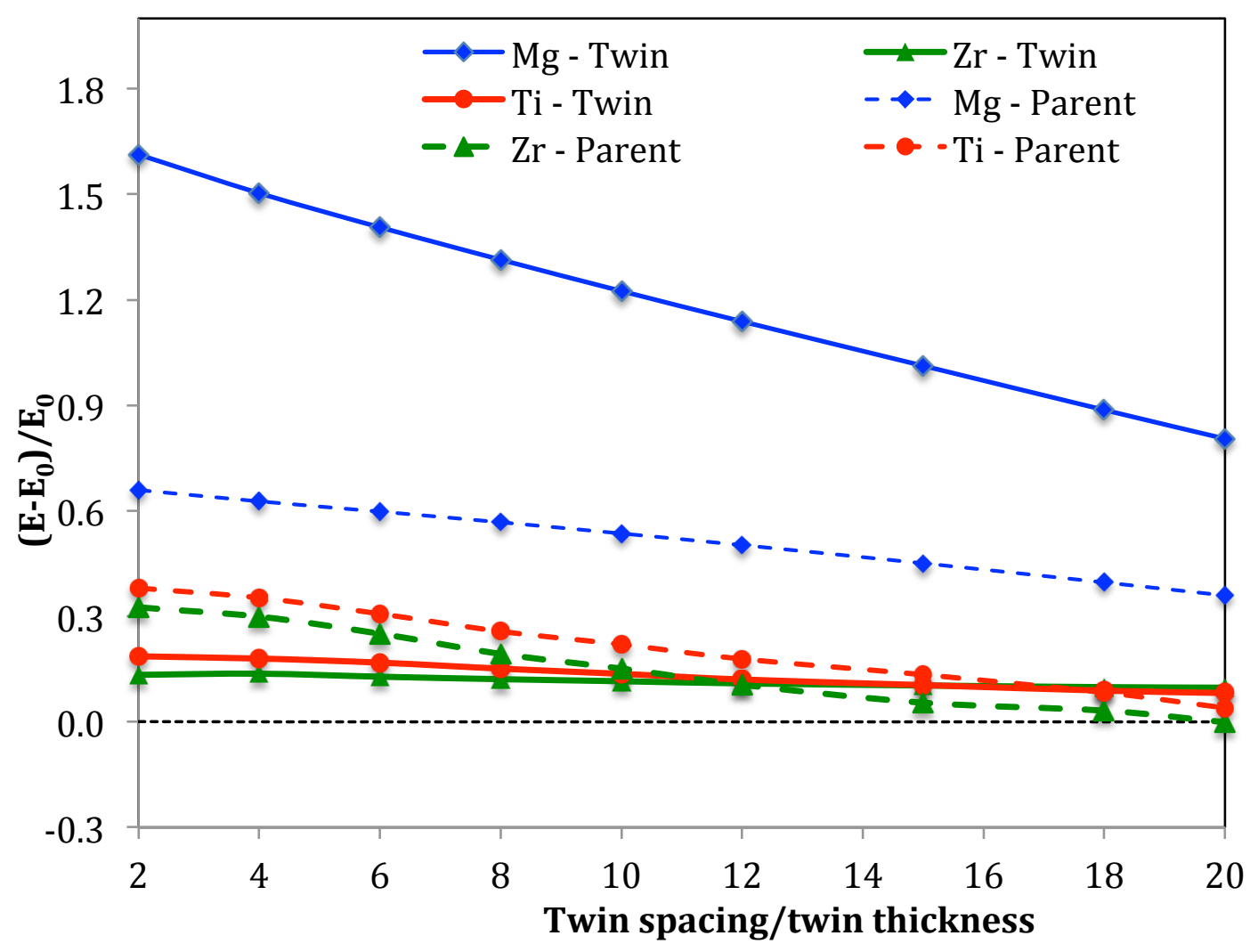

Figure 12: The relative difference in the average elastic energy in twin and in parent grain of two twin case $(E)$ with respect to the corresponding average elastic energy of an isolated twin case $\left(E_{0}\right)$ for $\mathrm{Mg}, \mathrm{Zr}$ and $\mathrm{Ti}$. The neighboring grain orientation is $\left(0^{\circ}, 0^{\circ}, 0^{\circ}\right)$, i.e., case- 0 . 
Graphical Abstragt istribution of Twin-plane resolved shear stress (TRSS) after twinning

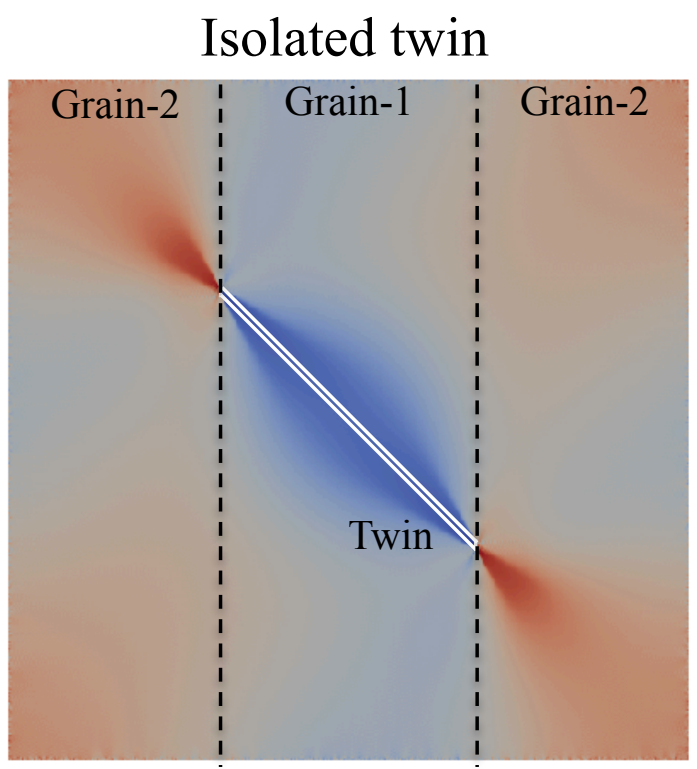

Twinning shear introduces a backstress in the twin and suppresses twin growth
Parallel twins $($ spacing $=2 \mathrm{t}$ )

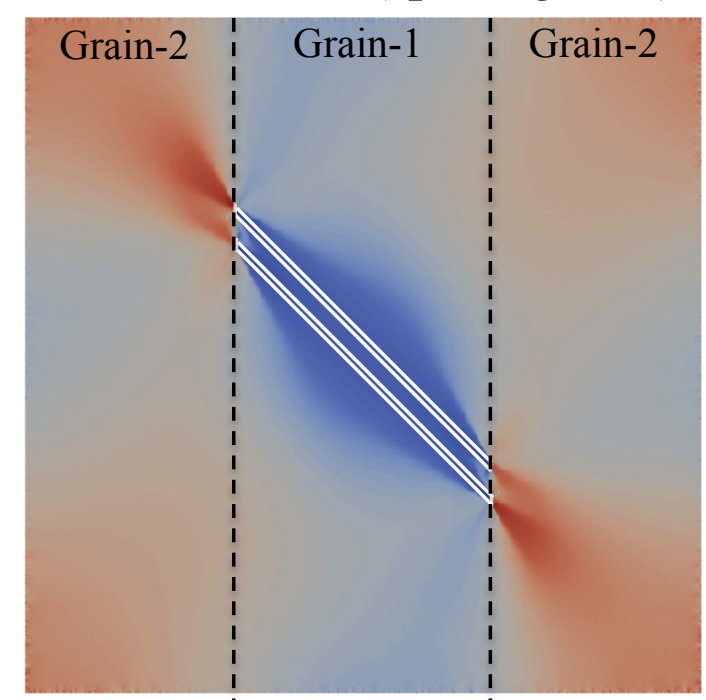

Closely spaced parallel twins interact each other and create more backstress than isolated twin
Parallel twins $($ spacing $=20 \mathrm{t})$

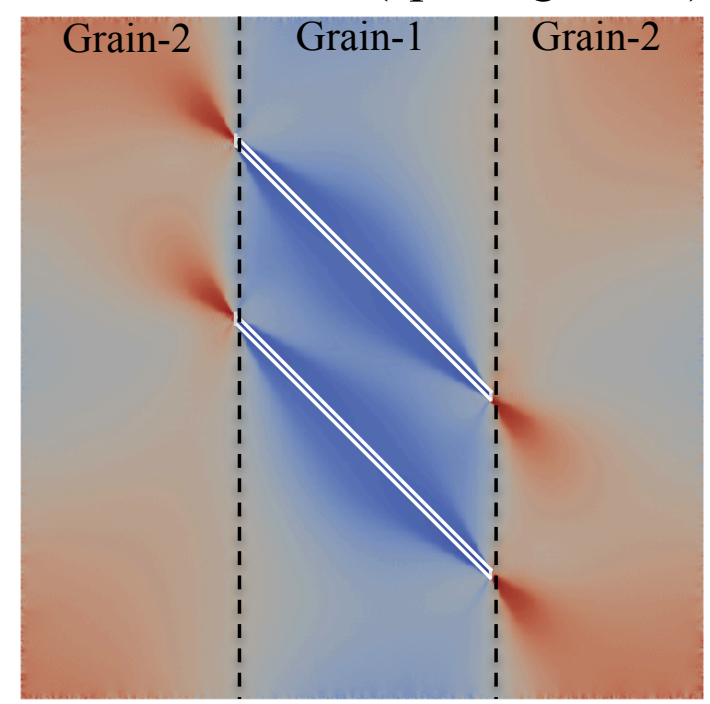

145

TRSS

Well separated parallel twins do not interact and hence do not enhance the backstress 